\title{
EXPERIMENTAL INVESTIGATION ON STABILITY OF INTACT AND DAMAGED COMBATANT SHIP IN BEAM SEA
}

Yue Gua ${ }^{a}$, Sandy Day**, Evangelos Boulougouris ${ }^{\mathrm{a}}$, Saishuai Dai ${ }^{\mathrm{a}}$

${ }^{a}$ Department of Naval Architecture, Ocean and Marine Engineering, University of Strathclyde, Glasgow, United Kingdom

*corresponding author: Email Address: sandy.day@strath.ac.uk (Sandy Day) 


\section{Experimental Investigation on Stability of Intact and Damaged}

\section{Combatant Ship in Beam Sea}

The stability of a damaged ship is influenced by several factors including encountered waves, ship motions, floodwater behaviour and interactions between ship motions and floodwater. The behaviour of floodwater is highly nonlinear so that a physical experiment is one of the best ways to obtain the assessment of damaged ship behaviour. The present study mainly addresses an experimental investigation on the stability of an intact and damaged combatant vessel in beam waves. Tests are carried out with a double-bottom naval combatant vessel DTMB 5415, which has been widely used in Benchmark studies for experimental investigation and the validation of numerical simulations. Free decay tests in roll with and without moorings are implemented in calm water, while the model is moored at the bow and stern during the tests in regular waves. In order to investigate the performance of the intact and damaged ship in the beam the damaged opening is located at starboard near the midship so that floodwater can ingress and egress from the opening where two compartments can be flooded. It is shown that beam waves flooding in and out from the damaged opening and the interaction between ship behaviour and water surface effect in the damaged compartments have a significant impact on ship motions and loads acting on the ship.

Keywords: Experimental assessment; DTMB 5415; Intact and damaged stability; Motions and wave-induced loads 


\title{
Experimental investigation on stability of intact and damaged combatant ship in beam sea
}

\author{
Yue Gua , Sandy Daya, Evangelos Boulougouris ${ }^{\mathrm{a}}$, Saishuai Dai ${ }^{\mathrm{a}}$ \\ ${ }^{a}$ Department of Naval Architecture, Ocean and Marine Engineering, University of Strathclyde, Glasgow, G4 OLZ, UK
}

\begin{abstract}
The stability of a damaged ship is influenced by several factors including encountered waves, ship motions, floodwater behaviour and interactions between ship motions and floodwater. The behaviour of floodwater is highly nonlinear so that a physical experiment is one of the best ways to obtain the assessment of damaged ship behaviour. The present study mainly addresses an experimental investigation on the stability of an intact and damaged combatant vessel in beam waves. Tests are carried out with a double-bottom naval combatant vessel DTMB 5415, which has been widely used in Benchmark studies for experimental investigation and the validation of numerical simulations. Free decay tests in roll with and without moorings are implemented in calm water, while the model is moored at the bow and stern during the tests in regular waves. In order to investigate the performance of the intact and damaged ship in the beam the damaged opening is located at starboard near the midship so that floodwater can ingress and egress from the opening where two compartments can be flooded. It is shown that beam waves flooding in and out from the damaged opening and the interaction between ship behaviour and water surface effect in the damaged compartments have a significant impact on ship motions and loads acting on the ship.
\end{abstract}

Keywords: Experimental assessment; DTMB 5415; Intact and damaged stability; Motions and wave-induced loads

\section{Introduction}

When a ship is damaged, compartments may be flooded and water may ingress and egress from the opening so that the ship may lose buoyancy and suffer different wave loading compared with the intact condition compounded by the reduction in structural integrity. The ship may experience heel and trim due to flooding, which affect floodwater behaviour, and further may cause sinking or even capsizing of the ship. The high non-linearity induced by the interaction between ship motions and floodwater is difficult to assess by potential theory or theoretical calculation. In order to investigate the flow caused by waves and resulting motions and the wave induced loading acting on the damaged ship, a physical experiment is one method suitable to study this complex phenomenon.

After a ship is damaged, it may suffer three main flooding stages, namely transient stage, intermediate stage and final stage (Ruponen 2007). In the transient stage, due to sudden damage such as collision, grounding and explosion, and subsequent floodwater ingress from the opening, the dynamic impact cannot be ignored as the transient heel angle may directly cause the ship to be non-recoverable. An experimental study by Santos et al. (2002) shows that a ship can capsize during transient flooding. During the intermediate stage, floodwater may continuously ingress and egress through the damaged opening from the damaged compartment., At this stage floodwater affects ship motions so that the interaction results in highly nonlinear behaviour of the ship. According to the study of Kim at al. (2017) the intermediate stage, requires extensive investigation to assess the motions of flooded ship, and is more challenging and fickle than other stages. Figure 1 shows the heel angle of flooded ship during the three main stages of flooding procedure.

\begin{tabular}{|llll|}
\hline \multicolumn{2}{ll|}{ Nomenclature } & \\
$\mathrm{A}$ & Wave amplitude & LCG & Longitudinal position of COG \\
$\mathrm{B}_{\mathrm{OA}}$ & Overall beam & $\mathrm{L}_{\mathrm{OA}}$ & Overall length \\
$\mathrm{B}_{\mathrm{WL}}$ & Beam at waterline & $\mathrm{L}_{\mathrm{PP}}$ & Length between perpendiculars \\
$\mathrm{C}_{\mathrm{B}}$ & Block coefficient & $\mathrm{L}_{\mathrm{WL}}$ & Length at waterline \\
$\mathrm{C}_{\mathrm{M}}$ & Midship section area coefficient & $\mathrm{T}$ & Draught \\
$\mathrm{C}_{\mathrm{P}}$ & Prismatic coefficient & $\mathrm{T}_{\mathrm{N}}$ & Natural period \\
$\mathrm{C}_{\mathrm{WP}}$ & Waterplane area coefficient & $\mathrm{T}_{\mathrm{w}}$ & Wave period \\
$\mathrm{COG}$ & Centre of gravity & $\mathrm{TM}$ & Torsional moment \\
\hline
\end{tabular}




\begin{tabular}{|llll|}
\hline $\mathrm{D}$ & Depth of ship & VBM & Vertical bending moment \\
$\mathrm{g}$ & Gravitational acceleration & VSF & Vertical shear force \\
$\mathrm{GM}$ & Transversal metacentric height & $\nabla$ & Displaced volume \\
$\mathrm{H}$ & Wave height & $\Delta$ & Displacement \\
$\mathrm{HBM}$ & Horizontal bending moment & $\lambda$ & Scale factor \\
$\mathrm{HSF}$ & Horizontal shear force & $\lambda_{w}$ & Wave length \\
$\mathrm{k}$ & Wave number & $\rho$ & Density of water \\
$\mathrm{KG}$ & Vertical position of COG & $\phi$ & Amplitude of roll motion \\
$\mathrm{KM}$ & Vertical position of metacentre & $\eta$ & Amplitude of heave motion \\
$\mathrm{k}_{\mathrm{xx}}$ & Radius of gyration with respect to roll & $\omega$ & Wave frequency \\
$\mathrm{k}_{\mathrm{yy}}$ & Radius of gyration with respect to pitch & $\omega_{\mathrm{E}}$ & Encounter wave frequency \\
$\mathrm{k}_{\mathrm{zz}}$ & Radius of gyration with respect to yaw & $\omega_{\mathrm{N}}$ & Roll natural circular frequency \\
& & & \\
\hline
\end{tabular}

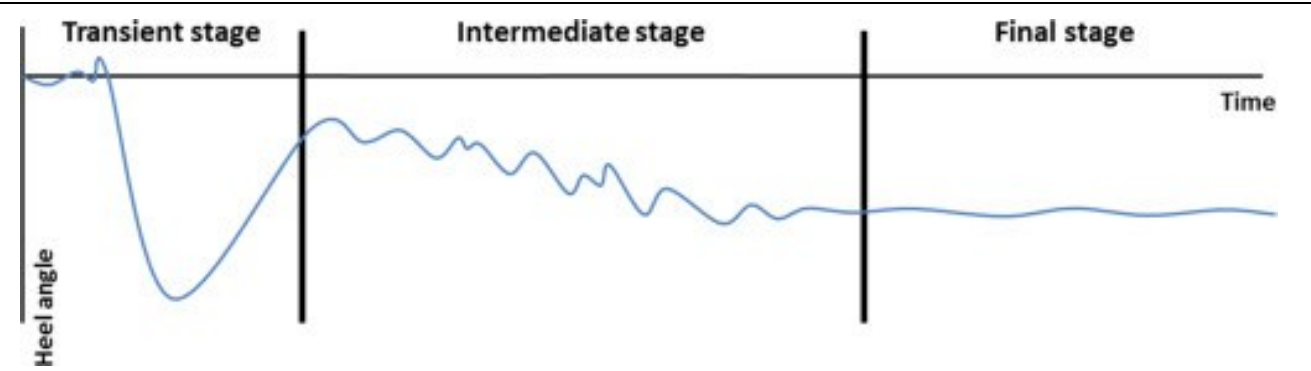

Figure 1. Main stages of flooding (Ruponen 2007)

In the past decades, Ro-Ro and cruise vessel accidents revealed that stability of passenger ship was still a relevant investigation for naval architects and researchers. Accidents to ships such as Estonia, Herald of Free Enterprise, European Gateway, and Sewol, illustrate that potential danger still exists for capsizing and loss of lives onboard. For Ro-Ro ships, violent and constrained motions of the floodwater can appear especially during flooding on the vehicle deck as there are typically no substantial barriers at vehicle deck level, e.g. watertight bulkhead or divided compartments to prevent the flows of floodwater and decrease the effect of free surface. To study the dynamic effects of the floodwater on deck, model experiments were carried out on passenger ships by Fujiwara and Haraguchi (2002), Papanikolaou et al. (1999, 2000), Santos and Soares (2008b). On the other hand, flooding into compartments has also attracted attention, and research on the different conditions of flooding into different compartments has been carried out with both experiments and numerical methods. A 4-meter box-shaped barge model with several compartments that can be flooded was developed and tested at TKK Ship Laboratory by Ruponen (2006). This model was further used by Manderbacka et al. (2015a, 2015b) to study the effect on the dynamic behaviour of a damaged ship and the floodwater progression among compartments. It is presented by studies that the difference in flooding and ship behaviour between undivided compartment and divided compartments is obviously large, and flooded compartments have a significant effect on floodwater and ship motions (Acanfora and Cirillo 2017; Gao et al. 2011; Manderbacka and Ruponen 2016).

Considering structural strength of damaged ship, investigation on global loads of the intact and damaged tankers and bulk carriers was assessed by researchers with numerical and experimental method. Numerical and experimental investigation on a Ro-Ro ship model was carried out by Chan et al. (2003) with intact and damaged scenarios at different wave headings. Global wave loads assessment was evaluated by a non-linear time domain method. Wu et al. (2002) and Santos and Soares (2008a) also applied a nonlinear time-domain simulation on the container ship model to study the effect of wave on the motions and loads that distributed along the ship. Detailed studies on structural strength analysis with evaluation of the vertical and horizontal bending moments on intact and damaged ships under the different damage scenarios were focused on by Khan and Das (2008) and Rodrigues and Soares (2017).

Warships, different from commercial ships, may have a high possibility to experience another type of damage, i.e. damage from launched weapons such as torpedoes and missiles, therefore, investigation of the stability and survivability of a damaged combatant ship is of current relevance. The transient effect of floodwater on a frigate model was investigated by Macfarlane et al. (2010). A 1/45-scale frigate model was used with latex membrane material used on the damaged opening to allow simulation of transient damage. Domeh et al. (2015) carried out experiments with a Leander class frigate model in a towing tank to study the damaged ship motions in waves considering different compartment permeability. Equipped 
with full appendages a 5-meter-long Leander class frigate model with relatively complex layout of the internal compartments was presented in experiments under the different loading conditions and sea states (de Kat and Peters 2002; Palazzi and de Kai 2004). Other towing tank tests were undertaken with Leander class frigate models to investigate the performance of damaged combatant ship considering the effect of regular and irregular waves, different damaged positions and advanced speed (Bennett et al 2013, 2014; Bennett and Phillips 2017).

As a well-known benchmark hull form, US Navy Destroyer model DTMB 5415 has been widely tested in model basins. Lee et al. (2012a) carried out small-scale experimental tests at Newcastle University. With detailed arrangement of each compartment global wave loads acting on the intact and damaged 1/100-scale ship hull are investigated under the different wave conditions and damaged scenarios, as well as wave induced loads. Begovic et al. (2017) carried out an experimental study on a 1/51 scaled DTMB 5415 at Kelvin Hydrodynamics Laboratory, University of Strathclyde, Glasgow, UK. Motions and wave loading acting on the intact and damaged ship model without forward speed were investigated in head and beam seas.

In the present work experiments are undertaken on the stability of intact and damaged combatant vessel in beam waves with a double-bottom naval combatant vessel DTMB 5415 at Kelvin Hydrodynamics Laboratory. A 3-meter ship model is used in model tests. Free rolling decay tests with and without restricted constraint are implemented in calm water, while the model is restrained at the bow and stern during the tests in regular waves. In order to investigate the performance of the intact and damaged ship in the beam sea it is perpendicular to the direction of wave coming without advanced speed, and the damaged opening locates at starboard near the midship so that floodwater can ingress and egress from the opening where two compartments will be flooded. Effects of dynamics of free surface due to floodwater on wave induced loads acting on intact and damaged ship hull are mainly investigated, and the experimental studies offer a valid benchmark data for corroboration with numerical approaches.

\section{Experimental setup}

\subsection{Description of laboratory and equipment}

Experimental tests are taken at Kelvin Hydrodynamics Laboratory, University of Strathclyde. The tank is equipped with a type of multi-flap absorbing wave maker and wave damping beach. Properties of the towing tank is shown in Table 1.

\begin{tabular}{ll} 
Table 1. Properties of towing tank at Kelvin Hydrodynamics Laboratory \\
\hline Properties & \\
\hline Length & $76 \mathrm{~m}$ \\
Width & $4.6 \mathrm{~m}$ \\
Depth & $2.15 \mathrm{~m}$ \\
\hline
\end{tabular}

During the physical tests, the 6 Degree-of-Freedom (DOF) motions of the ship are captured by a QUALISYS motion capture system. Wave elevation is measured by a wave probe, located more than $10 \mathrm{~m}$ up-wave of the model. Wave induced loads acting on the ship model are measured by a 5-DOF force gauge installed in the ship hull and all the tests are recorded on video by cameras positioned at the side of the tank.

\subsection{Description of ship model}

A 1:51 scaled model of DTMB 5415 is used during the tests. Particulars of the ship model are given in Table 2. The whole ship model has been divided by several compartments shown in Figure 2 and Figure 3. The damaged opening is located at the midship to starboard, facing the incoming direction of waves and two compartments can be flooded into when the cover on the damage opening is removed. The ship model is moored at bow and stern on soft elastic moorings so that the ship is not free to drift in regular beam waves, therefore, the model ship suffers beam waves with zero speed. It should be noted that the flooded compartments are ventilated by two pipes so that air compression effect can be eliminated when water floods into the damaged compartments from the opening shown in Figure 4 and Figure 5 .

Table 3 gives the particulars of damaged ship model after the cover on the damage opening is removed and the ship reaches the equilibrium condition in calm water. It is highlighted that the lost buoyancy 
method is used so that floodwater in the compartments is not treated as added mass of the ship after damage; the main particulars of damaged ship model remain but draft and buoyancy distribution have to be changed, where draft is increased and buoyancy in the flooded compartments disappears due to the water flooding.

Table 2. Particulars of intact DTMB 5415 model hull

\begin{tabular}{lll}
\hline Particulars & Full Scale & Model Scale \\
\hline Scale factor & 1 & 51 \\
$\mathrm{~L}_{\mathrm{OA}}$ & $153 \mathrm{~m}$ & $3 \mathrm{~m}$ \\
$\mathrm{~L}_{\mathrm{WL}}$ & $142 \mathrm{~m}$ & $2.784 \mathrm{~m}$ \\
$\mathrm{~B}_{\mathrm{OA}}$ & $20.5 \mathrm{~m}$ & $0.402 \mathrm{~m}$ \\
$\mathrm{~B}_{\mathrm{WL}}$ & $19.1 \mathrm{~m}$ & $0.374 \mathrm{~m}$ \\
$\mathrm{D}$ & $19.2 \mathrm{~m}$ & $0.376 \mathrm{~m}$ \\
$\mathrm{~T}$ & $6.16 \mathrm{~m}$ & $0.12 \mathrm{~m}$ \\
$\nabla$ & $8423.3 \mathrm{~m}^{3}$ & $0.0635 \mathrm{~m}^{3}$ \\
$\Delta$ & $8423.3 \mathrm{ton}$ & $63.5 \mathrm{~kg}$ \\
$\mathrm{C}_{\mathrm{B}}$ & 0.498 & 0.498 \\
$\mathrm{C}_{\mathrm{M}}$ & 0.818 & 0.818 \\
$\mathrm{C}_{\mathrm{P}}$ & 0.61 & 0.61 \\
$\mathrm{C}_{\mathrm{WP}}$ & 0.76 & 0.76 \\
$\mathrm{KM}_{\mathrm{N}}$ & $9.486 \mathrm{~m}$ & $0.186 \mathrm{~m}$ \\
KG & $7.548 \mathrm{~m}$ & $0.148 \mathrm{~m}$ \\
$\mathrm{GM}$ & $1.938 \mathrm{~m}$ & $0.038 \mathrm{~m}$ \\
$\mathrm{LCG}$ & $70.125 \mathrm{~m}$ & $1.375 \mathrm{~m}$ \\
$\mathrm{k}_{\mathrm{xx}}$ & $0.3 \mathrm{~B}$ & $0.3 \mathrm{~B}$ \\
$\mathrm{k}_{\mathrm{yy}}$ & $0.25 \mathrm{~L}$ & $0.25 \mathrm{~L}$ \\
$\mathrm{k}_{\mathrm{zz}}$ & $0.25 \mathrm{~L}$ & $0.25 \mathrm{~L}$ \\
\hline & & \\
\hline & & \\
\hline
\end{tabular}

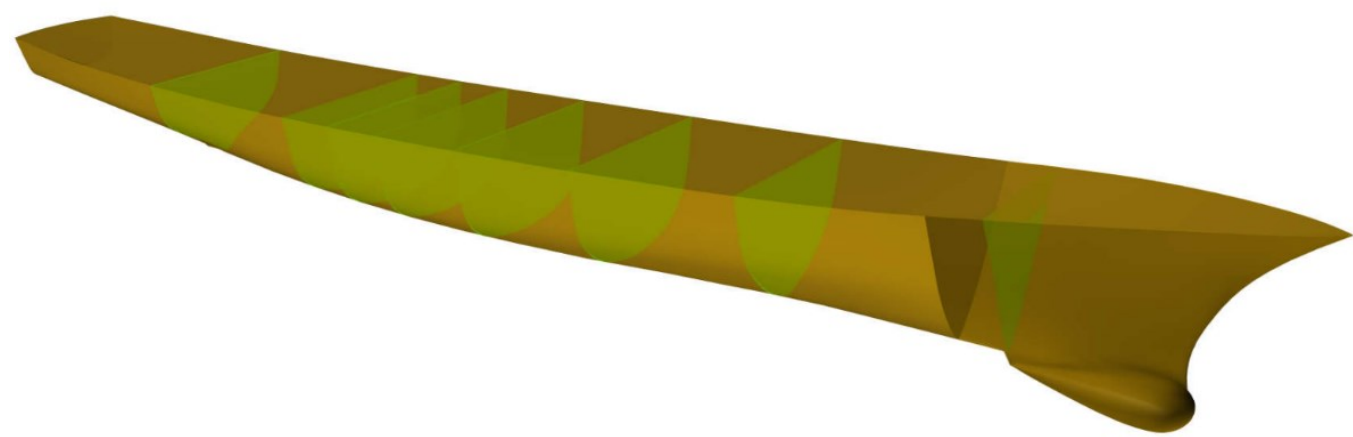

Figure 2. Ship model with compartments

Table 3. Particulars of damaged ship model

\begin{tabular}{ll}
\hline Particulars & \\
\hline $\mathrm{L}_{\text {flooded }}$ & $0.4685 \mathrm{~m}$ \\
$\mathrm{~T}$ & $0.145 \mathrm{~m}$ \\
$\mathrm{~B}_{\mathrm{WL}}$ & $0.382 \mathrm{~m}$ \\
\hline
\end{tabular}




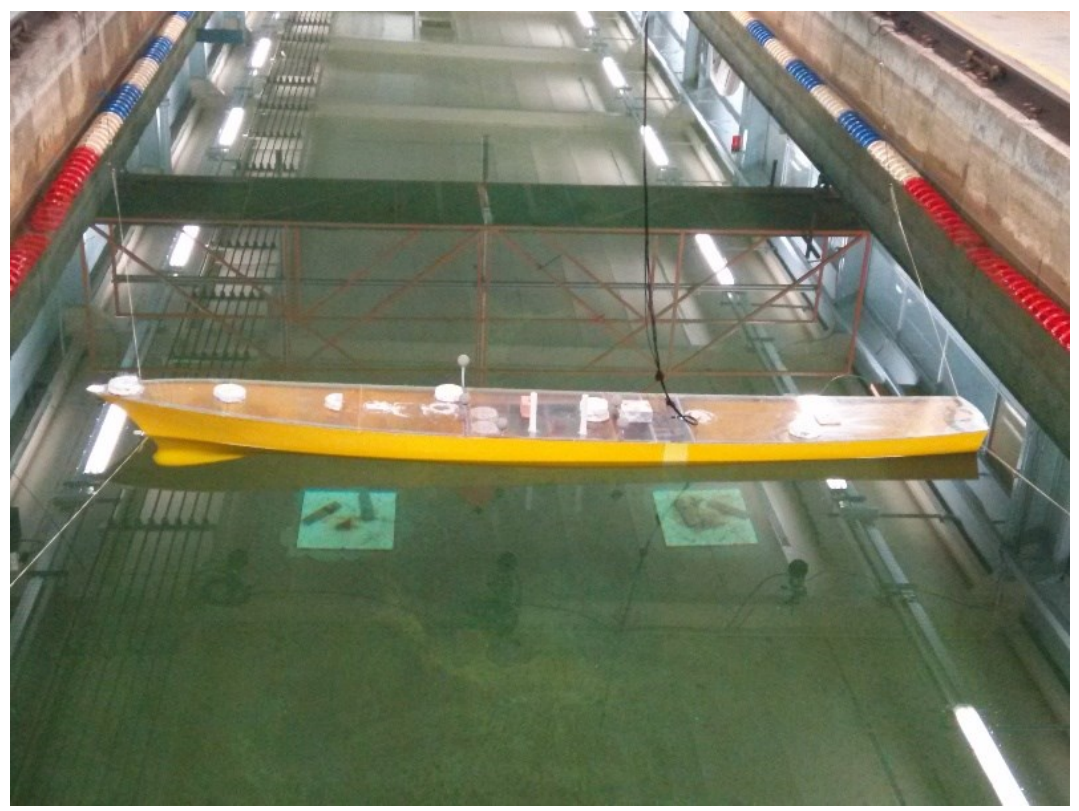

Figure 3. Experimental setup

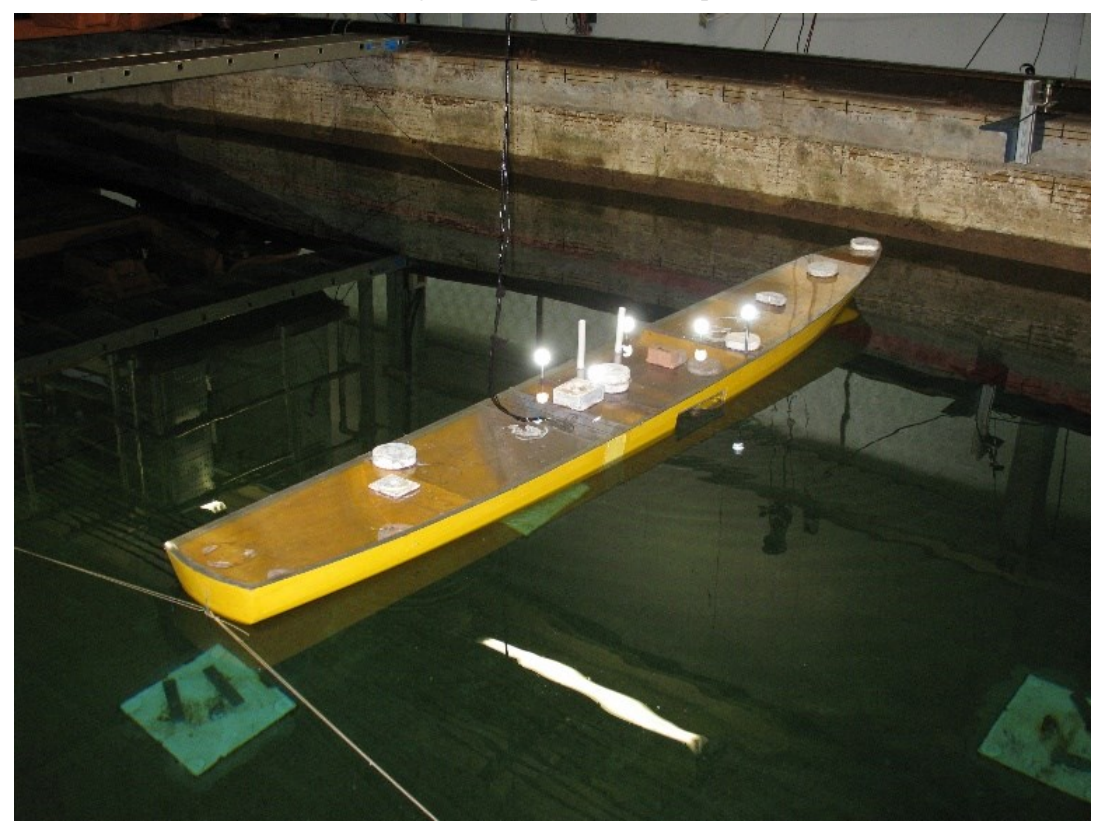

Figure 4. Damaged ship model

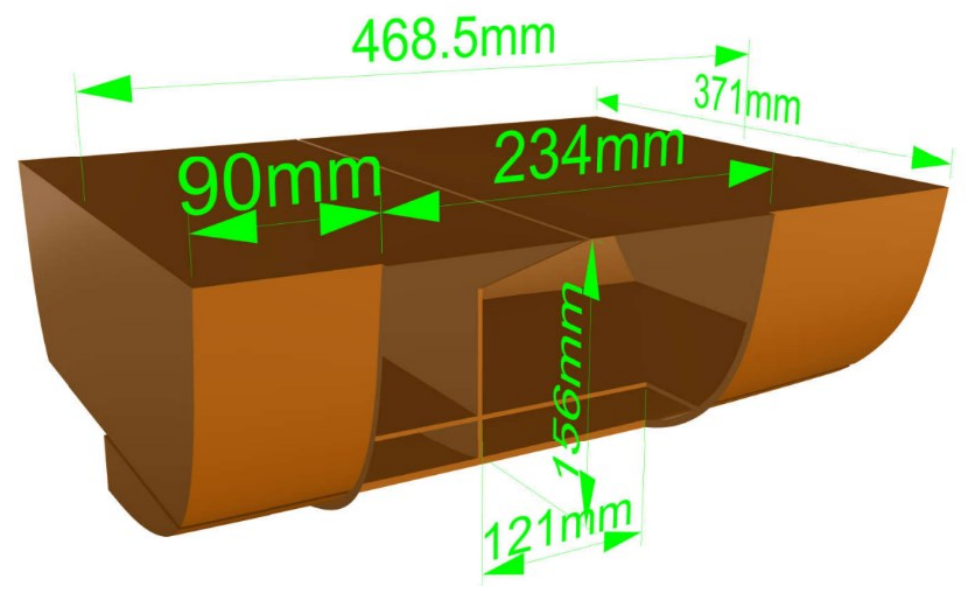

Figure 5. Flooded compartments with dimensions 


\subsection{Description of test conditions}

Free decay tests with and without moorings in calm water were conducted prior to the seakeeping tests in beam waves. It should be noted that initial angle of all the decay tests is started with vessel heeled to portside, which is the undamaged side of the ship, to make sure that damaged opening does not completely submerge under the water.

For the tests in waves, a series of regular beam waves are created by wave maker; the amplitude of the waves varied from $5 \mathrm{~mm}$ to $15 \mathrm{~mm}$ while the period of the waves ranged from $0.7 \mathrm{~s}$ to $2.5 \mathrm{~s}$ in both intact and damaged scenarios. Wave elevation is captured along with time by wave probe positioned upwave of the ship model. For each test, data collection, including waves, ship motions and wave-induced loads, was run until the motions reached a stable periodic state for a period of around ten oscillations. After each test, side beaches are raised to accelerate damping effect to water surface so that next test should not be affected.

Details of the waves are given as Table 4.

\begin{tabular}{ll}
\multicolumn{2}{c}{ Table 4. Regular beam wave setting } \\
\hline $\mathrm{H}$ & $\mathrm{T}_{\mathrm{w}}$ \\
\hline $20 \mathrm{~mm}$ & $0.7 \mathrm{~s}, 0.84 \mathrm{~s}, 0.98 \mathrm{~s}, 1.12 \mathrm{~s}, 1.26 \mathrm{~s}, 1.4 \mathrm{~s}, 1.47 \mathrm{~s}$, \\
$10 \mathrm{~mm}, 20 \mathrm{~mm}, 25 \mathrm{~mm}, 30 \mathrm{~mm}$ & $1.51 \mathrm{~s}, 1.54 \mathrm{~s}, 1.56 \mathrm{~s}, 1.58 \mathrm{~s}, 1.61 \mathrm{~s}$ \\
$20 \mathrm{~mm}$ & $1.68 \mathrm{~s}, 1.82 \mathrm{~s}, 1.96 \mathrm{~s}, 2.1 \mathrm{~s}, 2.24 \mathrm{~s}, 2.38 \mathrm{~s}, 2.52 \mathrm{~s}$
\end{tabular}

\section{Test procedure}

\subsection{Free decay tests in calm water}

As mentioned above, free decay tests are undertaken with and without mooring restraint in still water to determine the natural frequency of the ship model; the roll motion of intact and damaged ship model is presented in Figure 6. It is clearly observed that the equilibrium heel of damaged scenario is at approximately 2 degrees approximately. The reason for this is that as shown in Figure 5, when water floods into the compartments, the double bottom is not fully filled with floodwater, instead, only half (starboard side) of bottom space can be flooded due to the damage. Finally, when ship reaches its upright state it heels to the damaged side.

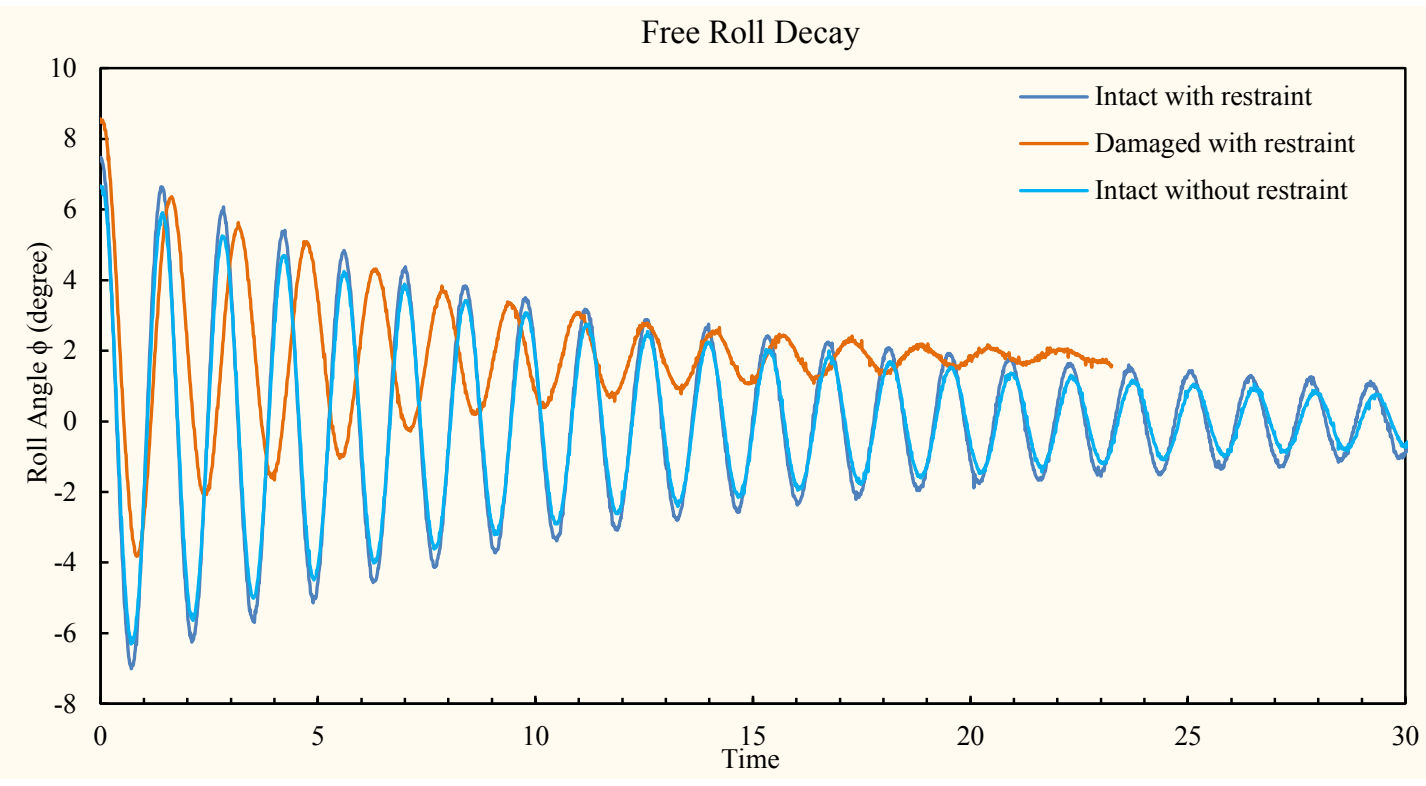

Figure 6. Time history of free roll angle reduction

\subsection{Free sway decay tests with restraint in calm water}

Figure 7 shows the decay curve about the free sway motion under the intact and damaged condition. Ship model in both tests is restrained all the time. Even though fluctuating water surface may affect the 
decay motion in sway motion under the damaged condition, due to the depth of water in the compartment is larger enough than the height of double-bottom space, it has no dynamic influence on the doublebottom space so that sloshing phenomena only appears at flooded compartments, rather than the flooded double-bottom domain.

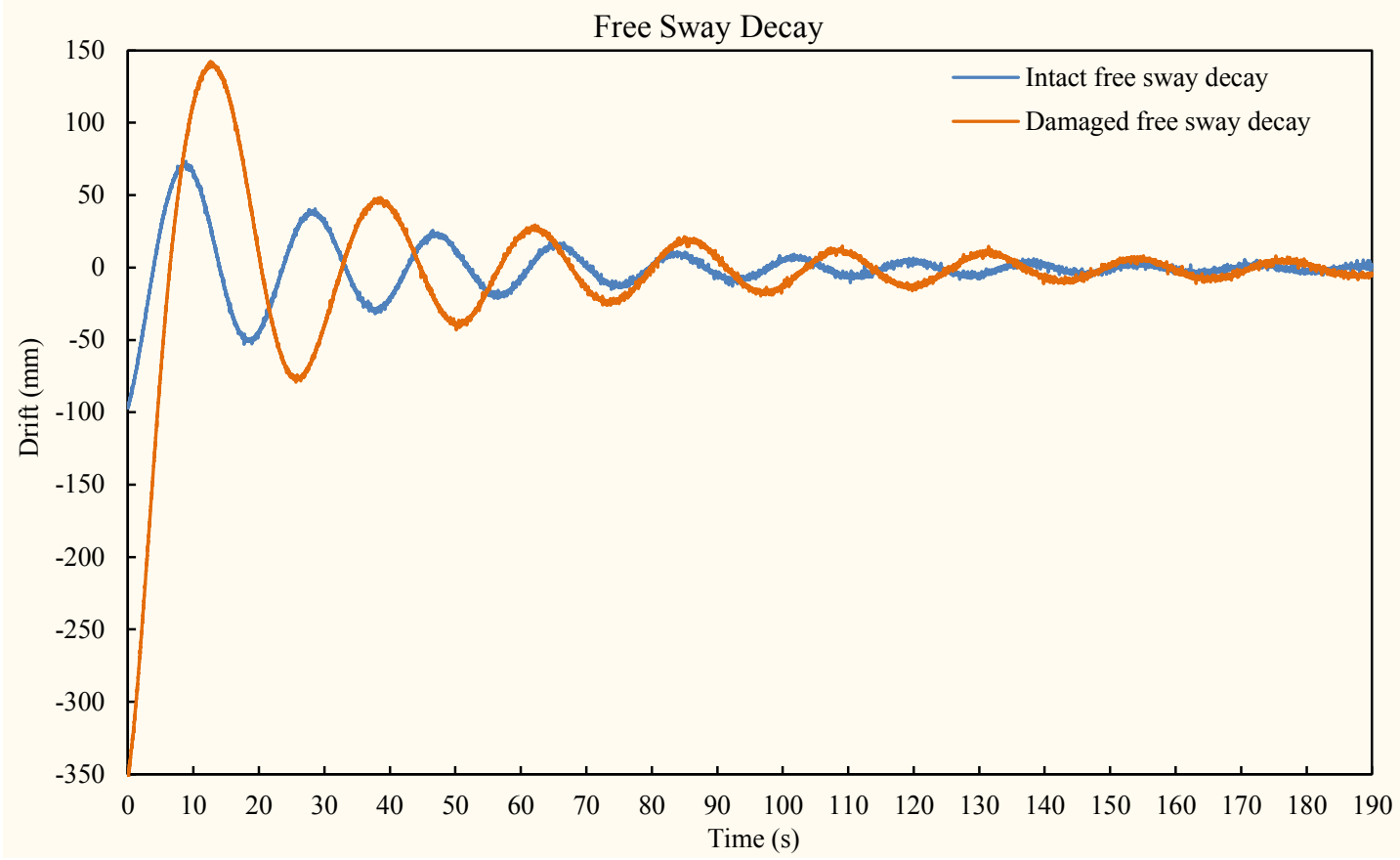

Figure 7. Time history of free sway decay

\subsection{Tests in beam waves}

The ship motions and loads action on the ship model are measured for all the intact and damaged cases in regular beam waves. Again, $20 \mathrm{~mm}$ wave height is created for the full range of frequencies by wave maker, and $10 \mathrm{~mm}$ to $30 \mathrm{~mm}$ wave heights are also tested around the natural frequency as shown in Table 4 at Section 2.3.

The intact ship is first tested followed by the damaged cases. By removing the damaged opening at starboard and after the damaged ship stabilizes at static equilibrium, the damaged case is started. Figure 8 gives a sample of wave elevation and ship behaviour responding to the encountered wave.

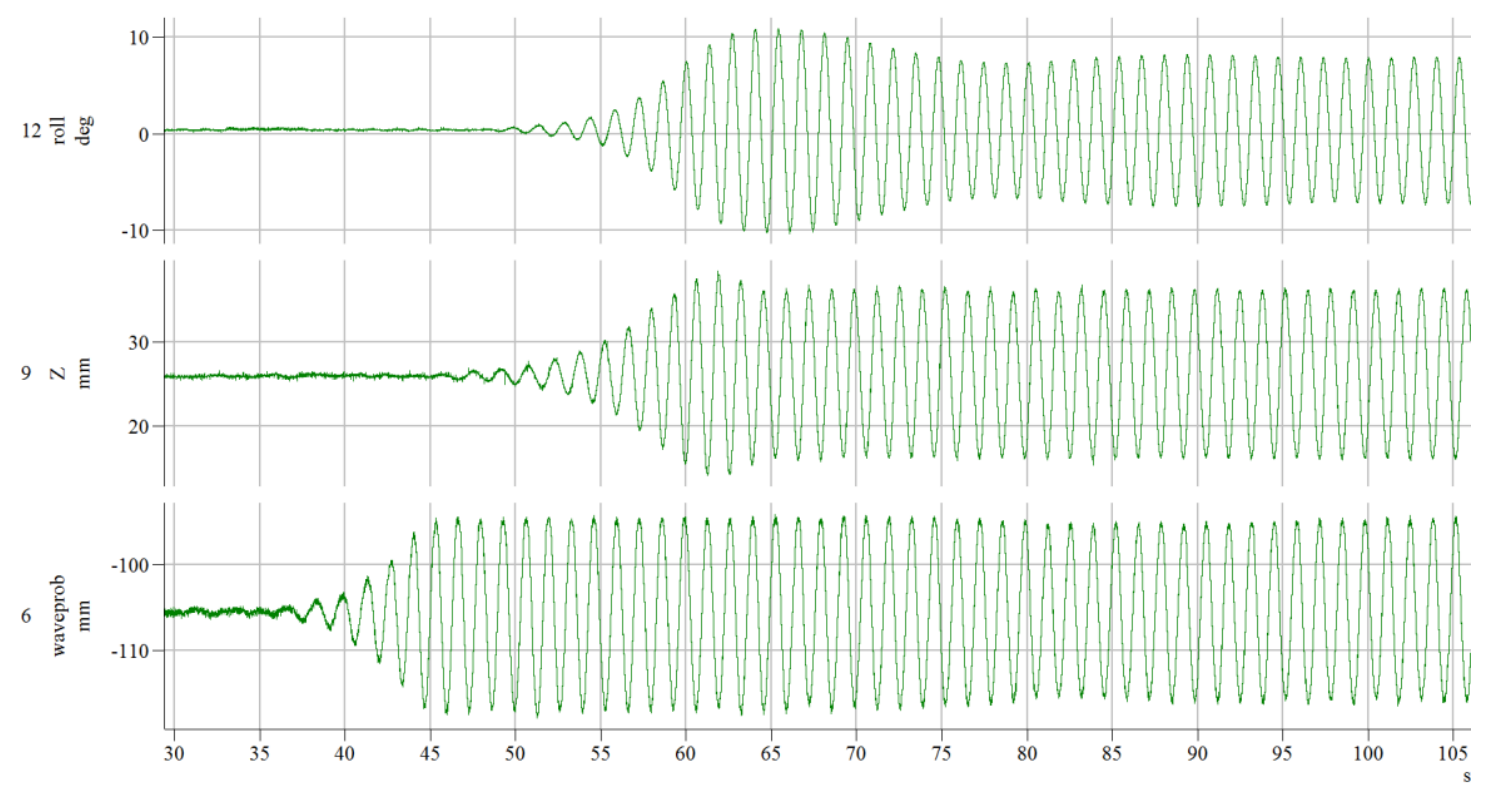

Figure 8 . Measured wave elevation and ship behaviour 
Besides, wave induced loads acting on the intact and damaged ship model are of significance for stability and survivability of vessel. Specifically speaking, during the tests two shear forces - vertical shear force and horizontal shear force, and three moments - vertical bending moment, horizontal bending moment and torsional moment are measured under both intact and damaged scenarios, as shown in Figure 9. A sample of measured wave-induced loads on the model hull is given as Figure 10. It can be seen clearly that due to the floodwater an obvious nonlinearity shown on the loads acting on the damaged ship $\left(\mathrm{M}_{\mathrm{x}}\right)$ in Figure 10 .
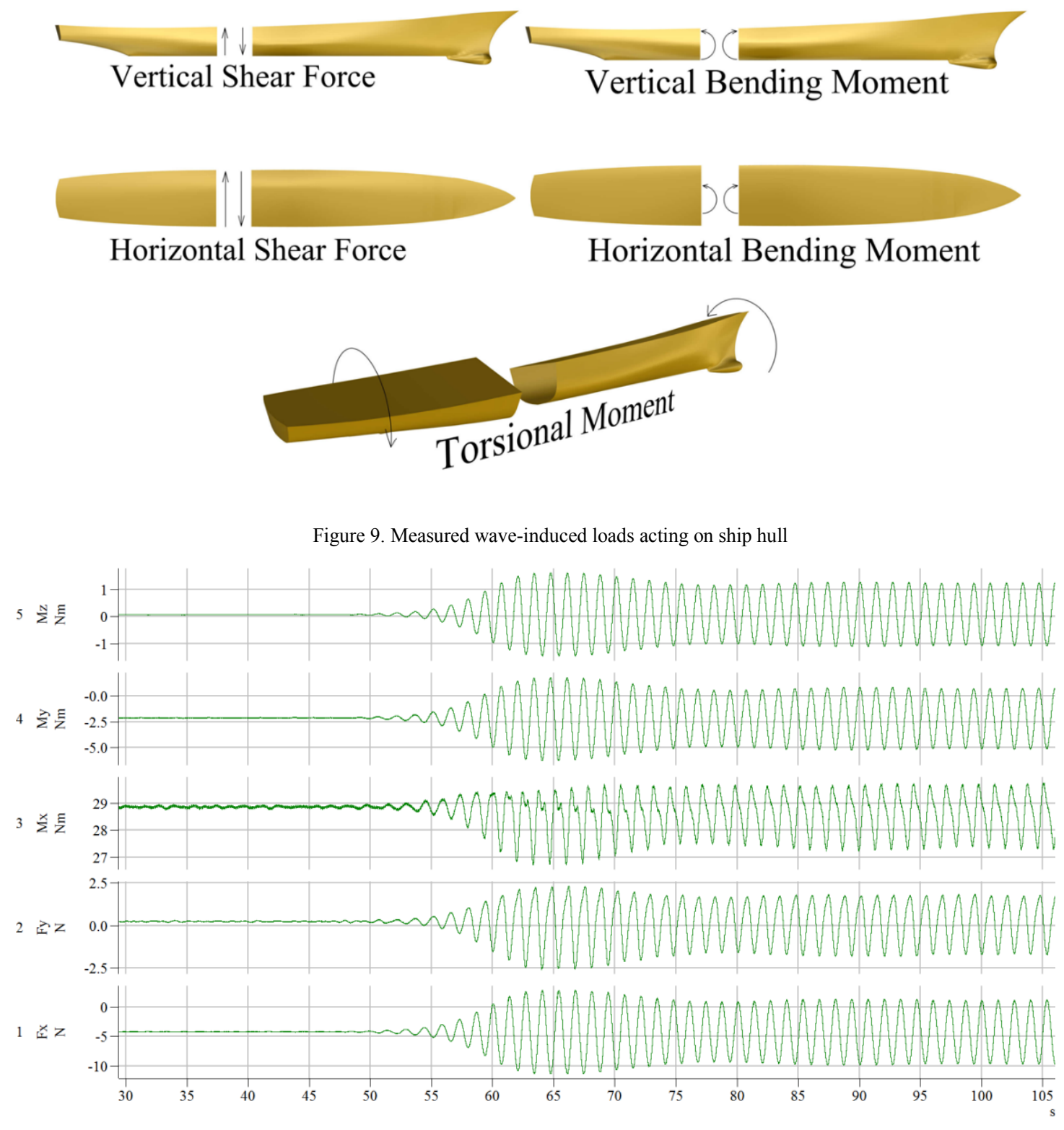

Figure 10. Wave-induced loads

Prior to the tests in the tank, the weight, mass moment of inertia, location of the centre of gravity and radii of gyration of the rotational motion of the ship model have been measured, see Table 2 .

\section{Results and discussion}

\subsection{Free decay tests}

To determine the natural frequency of the ship model, free decay tests on roll motion and sway motion with and without restraint are carried out by forcing a rotational angle or transversal displacement to the 
ship hull. Through Fourier Transform algorithm the natural frequency of the ship model can be given as Figure 11 and Figure 12.

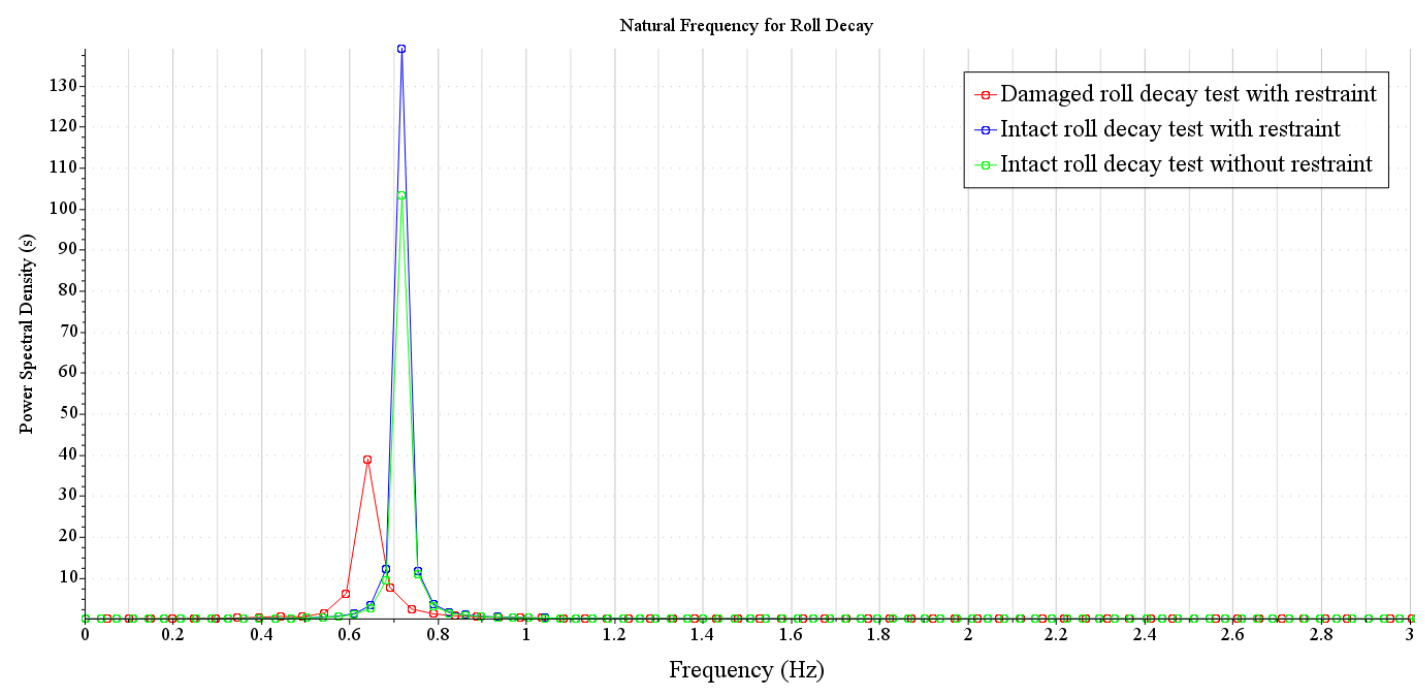

Figure 11. Natural frequency for roll decay

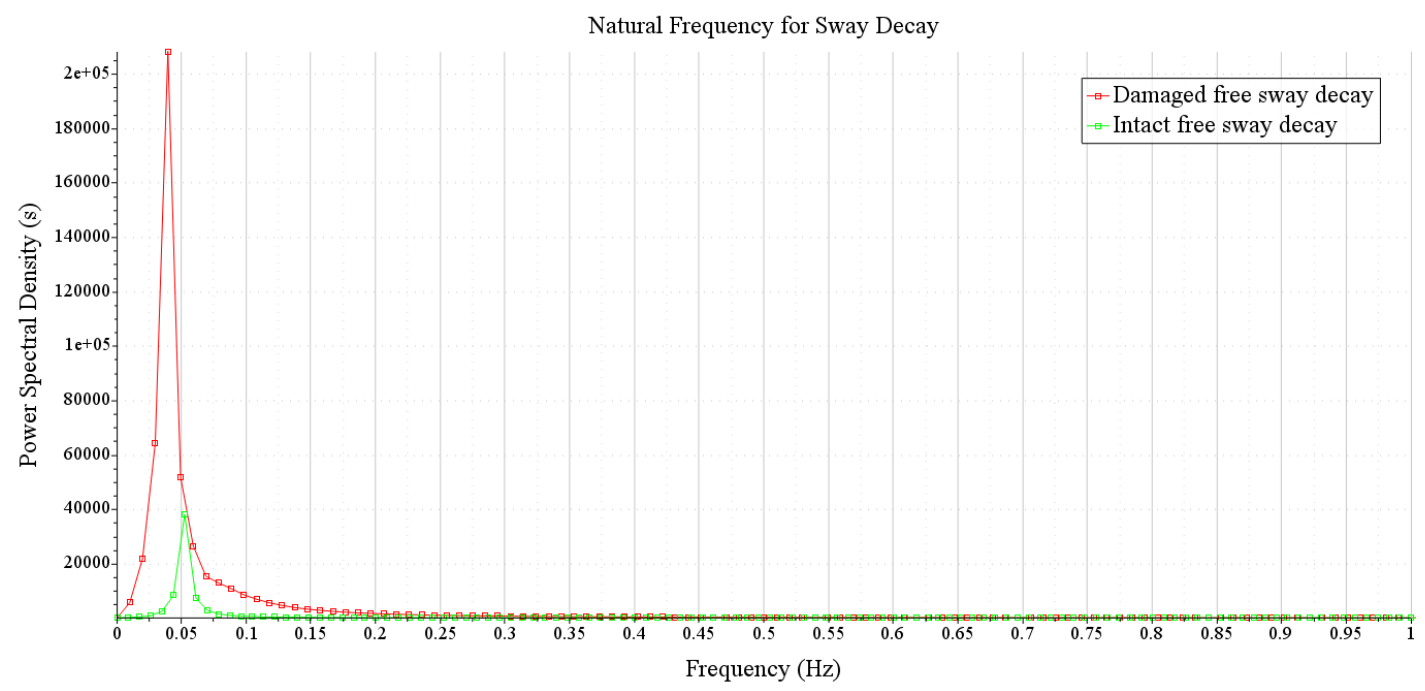

Figure 12. Natural frequency for sway decay

Meanwhile, the roll damping coefficient is analyzed by using a numerical optimization technique to find the best fit to the measured time history. The time history is generated by using a $4^{\text {th }}$ order RungeKutta method to solve the equation of roll motion. This is implemented for three cases: linear mass, damping and restoring items, linear mass and restoring with quadratic damping, and linear mass, quadratic damping and cubic restoring as shown respectively in Equation 1 to Equation 3 below.

$$
\begin{gathered}
\left(I_{x x}+A_{x x}\right) \ddot{\theta}+b_{1} \dot{\theta}+k_{1} \theta=0 \\
\left(I_{x x}+A_{x x}\right) \ddot{\theta}+b_{1} \dot{\theta}+b_{2} \dot{\theta}|\dot{\theta}|+k_{1} \theta=0 \\
\left(I_{x x}+A_{x x}\right) \ddot{\theta}+b_{1} \dot{\theta}+b_{2} \dot{\theta}|\dot{\theta}|+k_{1} \theta+k_{3} \theta^{3}=0
\end{gathered}
$$

where

$I_{x x}$ is the mass moment of inertia of roll motion

$A_{x x}$ is the added mass moment of inertia of roll motion

$b_{1}$ is the linear damping coefficient

$b_{2}$ is the quadratic damping coefficient

$k_{l}$ is the linear restoring coefficient

$k_{3}$ is the cubic restoring coefficient

$\theta$ is angle of roll motion 
Table 5. Natural frequency, period and linear damping coefficient

\begin{tabular}{lccc}
\hline & Natural Frequency $(\mathrm{Hz})$ & Natural Period (s) & Linear Damping Coefficient \\
Intact roll decay with restraint & 0.7173 & 1.394 & 0.167 \\
Damaged roll decay with restraint & 0.6391 & 1.565 & 0.441 \\
Intact roll decay without restraint & 0.7173 & 1.394 & 0.175 \\
Intact sway decay with restraint & 0.0522 & 19.157 & 5.225 \\
Damaged sway decay with restraint & 0.0392 & 25.510 & 9.242 \\
\hline
\end{tabular}

By varying the values of the various equation parameters, including the damping coefficients sought, the root-mean-square errors (RMSE) between the time histories measured in the experiments and those generated using 3 equations above are minimized using the Generalized Reduced Gradient (GRG) method. Results show a good agreement between measured data and generated values. It is found that a good fit is achieved for the intact ship even for the linear case, and a slightly better fit over the whole range is obtained using quadratic damping. The summary of results about roll decay tests for intact and damaged scenarios including the natural frequencies, natural periods and damping coefficients can be made as Table 5. It can be noted that natural frequency under the damaged condition is smaller than intact condition and water surface effect in the damaged compartment under the damaged condition increases damping to ship motions, as highlighted also by De Kat (2002); Lee et al. (2012b); Manderabacka et al. (2015b); Papanikolaou and Spanos (2004).

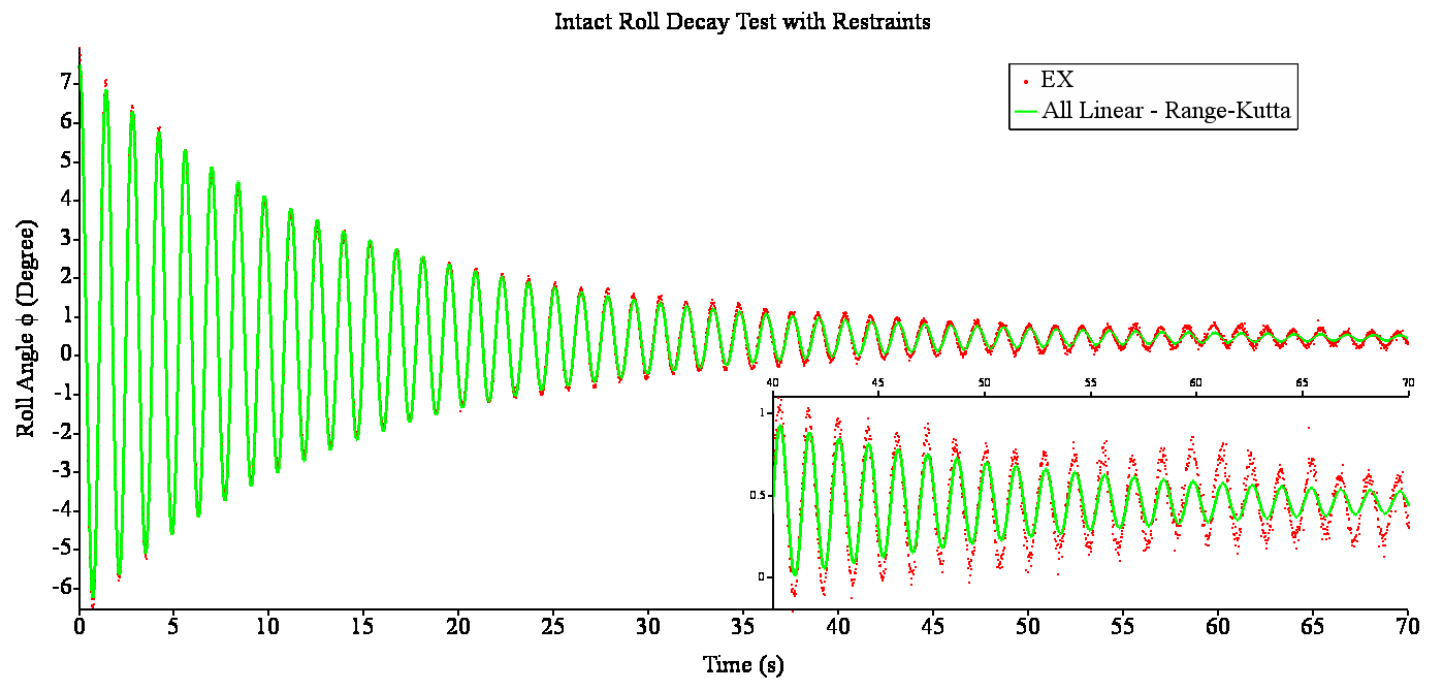

Intact Roll Decay Test with Restraints

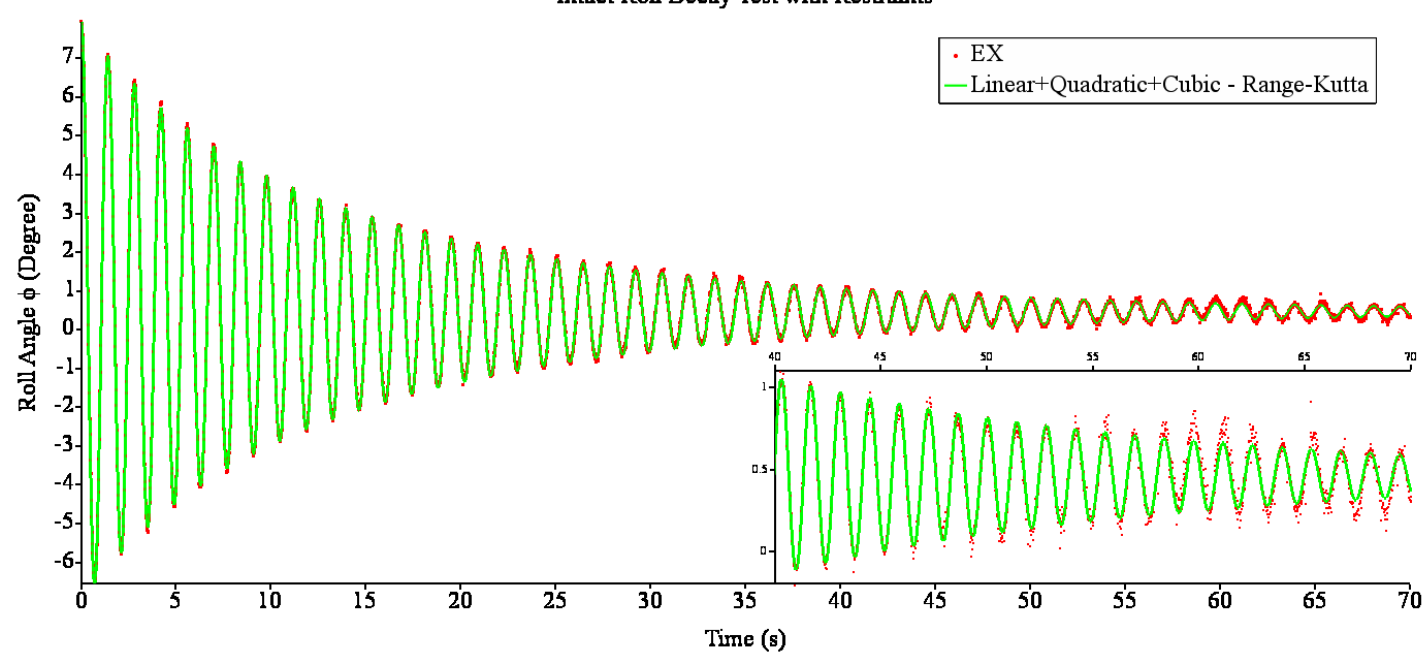




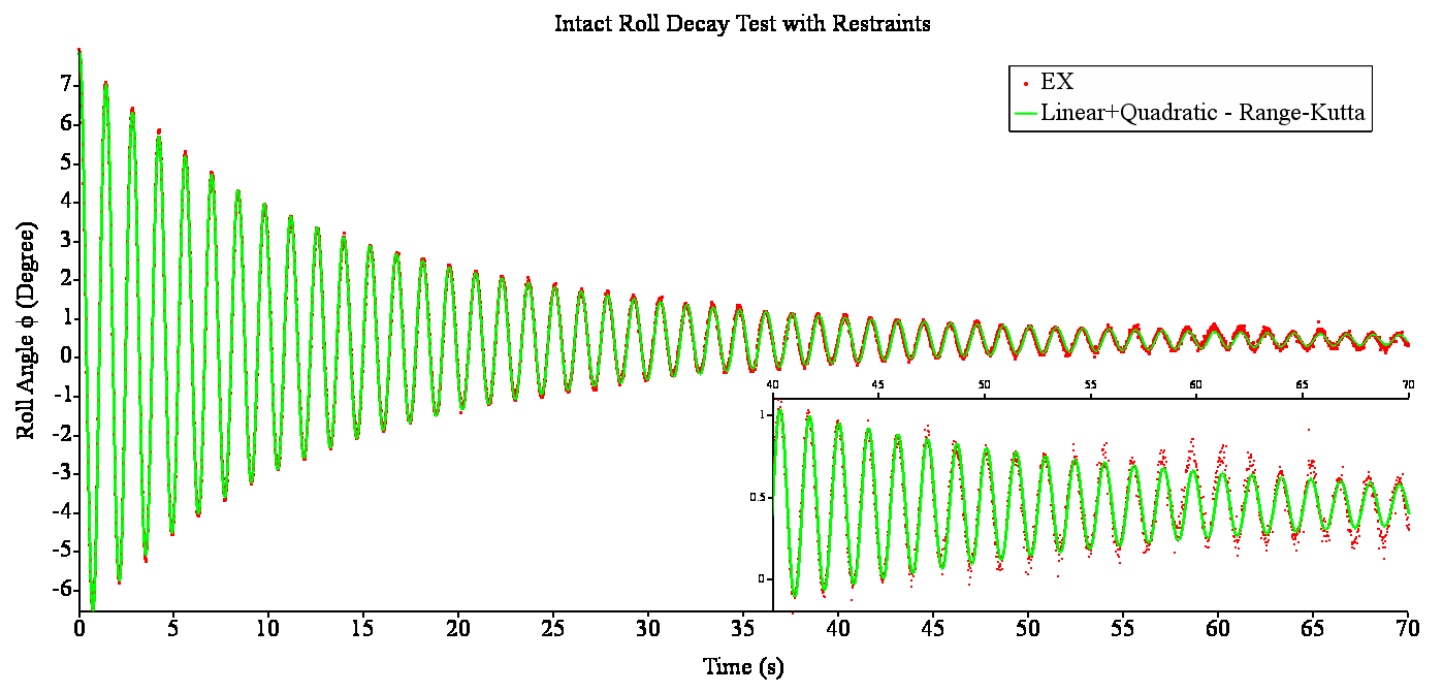

Figure 13. Intact roll decay test with restraints VS Runge-Kutta method

Taking intact roll decay test with restraints for instance, Figure 13 shown above presents comparisons between experimental data and generated values among three roll motion equations (Equation 1 - 3) linear mass, damping and restoring; linear mass, quadratic damping and linear restoring; linear mass, quadratic damping and cubic restoring. Values between 40 s to 70 s are zoomed in to a plot located at right corner in each figure. Although a good agreement was achieved for each case, generated values are different when roll angle fluctuates relatively small around equilibrium level (during 40s to 70s), which is assembled to be shown in Figure 14. It can be seen that using quadratic damping with linear restoring gives a better agreement with measured data compared with using linear damping with linear restoring, but using quadratic damping with cubic restoring item seems not to present obviously a much better evolution.

It can be observed that damage has a significant influence on the ship performance. More specifically, due to floodwater's ingress and egress, it increases the natural period by approximately $12 \%$ compared with the intact scenario. Meanwhile, the water surface effect in the flooded compartments also plays an essential role as an additional damping effect on the ship motion to some extent. Similar effect for floodwater acting on the free sway motion can be presented as well, while the damping effect is not so remarkable as for free roll motion. It can be deemed that the damping effect of damage and floodwater is attributed to sloshing and viscous effects. Compared with intact scenario, motion of damaged ship is affected additionally by water sloshing in the damaged compartment and ingress/egress process through damage opening, which can exert more viscous influence on the ship motion such as vortex generation and radiation wave generation, and these phenomena can be apparently observed during the tests (take Figure 4 as an example, it is clear to be seen that radiation wave is generated at the damage opening). It will be better described and explained at RAOs of ship motions and wave-induced loads in beam seas.

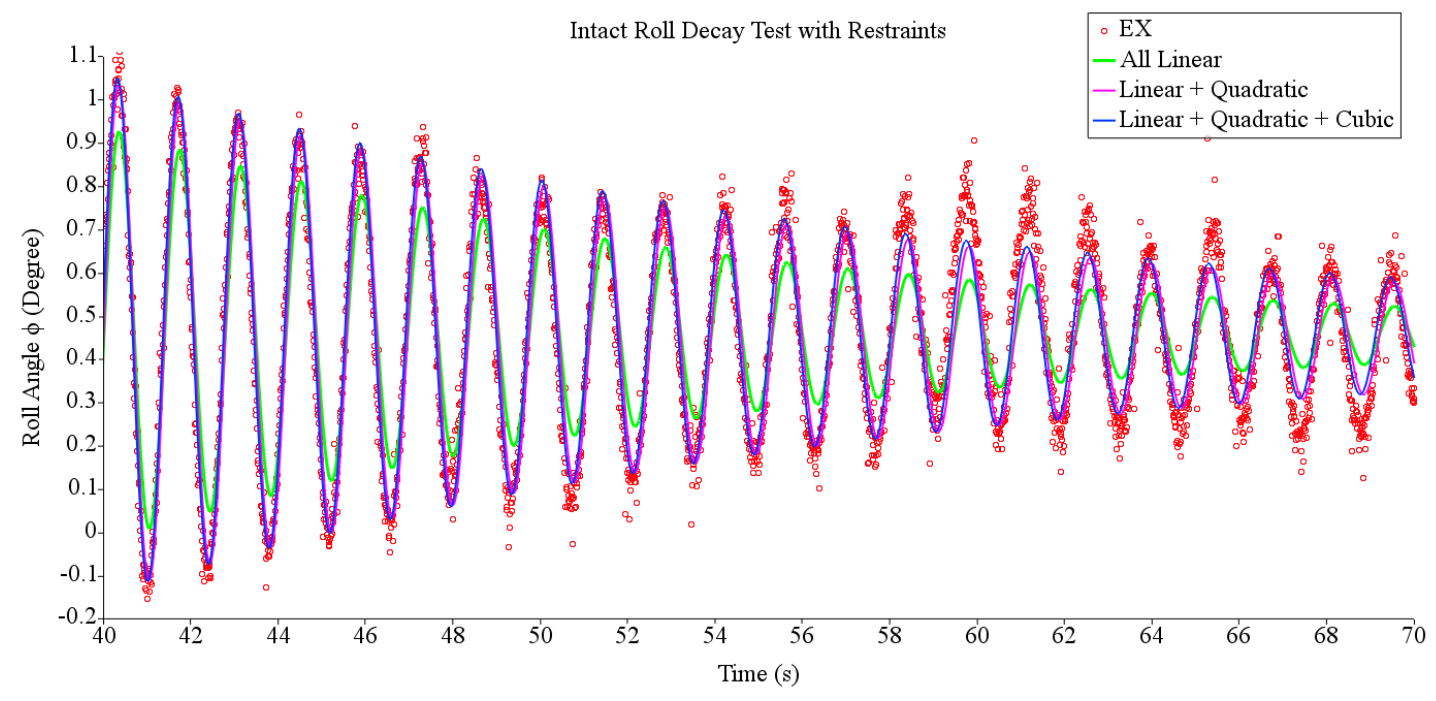

Figure 14. Intact roll decay test with restraints VS Runge-Kutta method (40s to 70s) 
On the other hand, from Table 5 it can be seen that restraint does not significantly affect ship's roll motion, which is the main aspect of investigation in this study - roll frequencies are almost identical, and the difference of damping coefficient is about $4.79 \%$ between restrained and non-restrained scenarios.

Non-dimensional Roll RAO

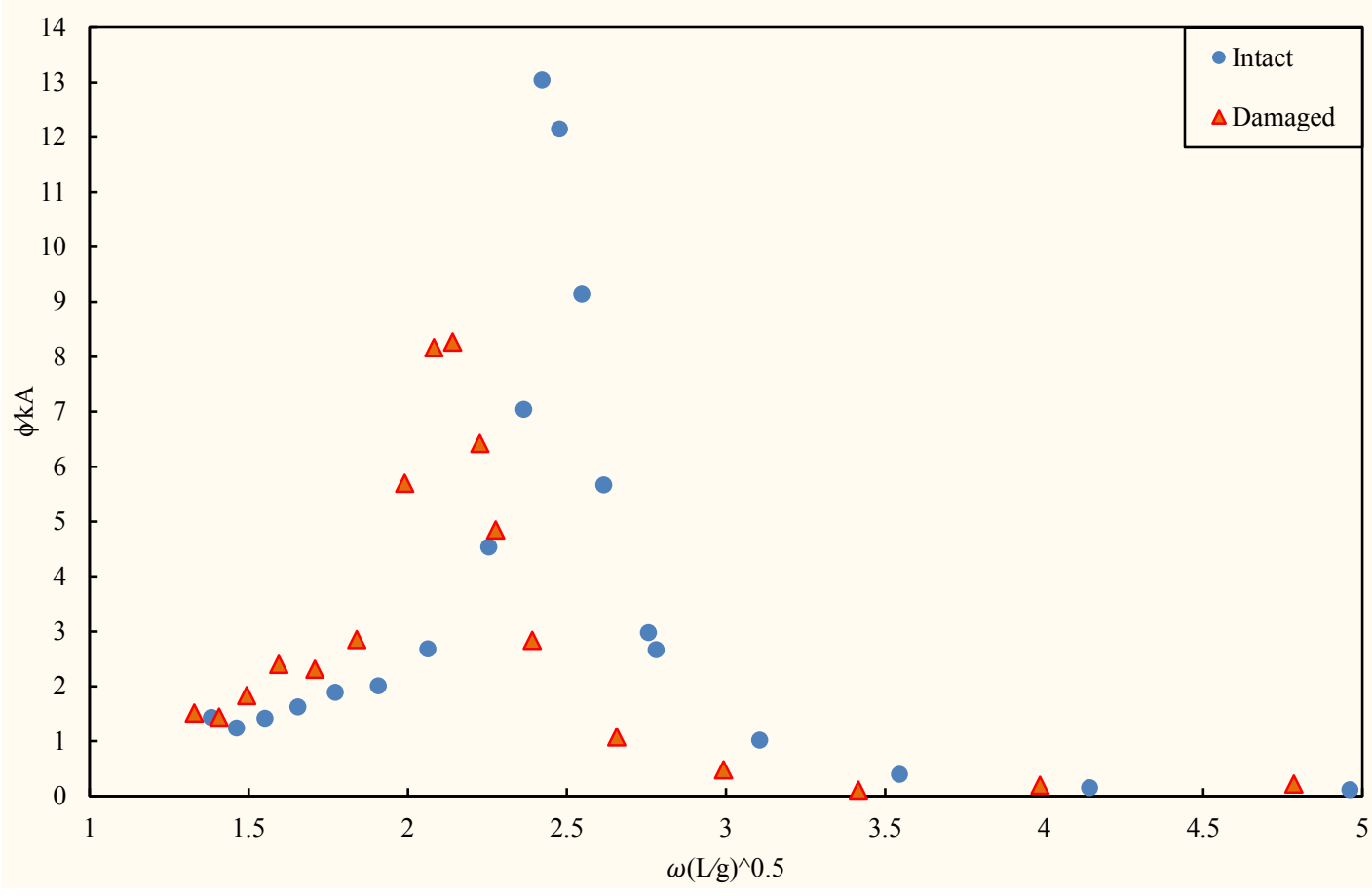

Figure 15. Non-dimensional roll motion

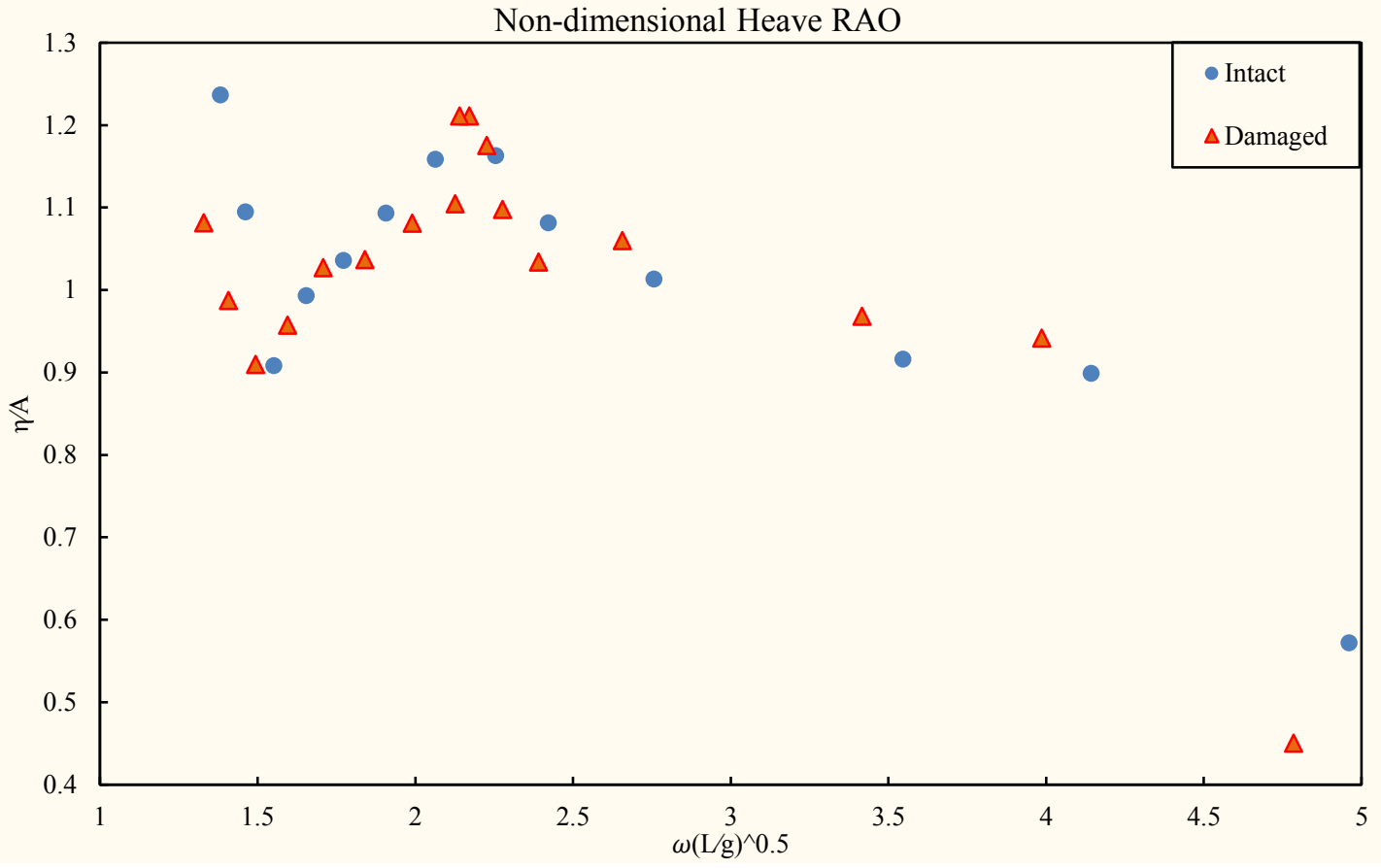

Figure 16. Non-dimensional heave motion

\subsection{Ship motions in beam seas}

In beam waves, the model is restrained at each case with soft elastic moorings. Roll and heave motion are measured under the intact and damaged scenarios. RAOs of roll and heave motion are nondimensionalized by kA and A, while frequency is non-dimensionalised by multiplying by $(\mathrm{L} / \mathrm{g}) 0.5$. 
Figure 15 and Figure 16 show the non-dimensional RAOs of intact and damaged ship motions in beam waves relative to non-dimensional frequencies.

It may be observed that resonance of the intact ship roll motion occurs at higher frequency than that for the damaged ship. The floodwater not only increases reactive time in roll but also imposes extra damping on the ship roll motions However, resonance frequencies of heave motion for intact and damaged cases are not so clearly different. Furthermore, there is no large difference in magnitude of heave RAOs between intact and damaged cases. It should be noticed that for low non-dimensional frequency (less than 1.3) heave motion seems not to be measured accurately.

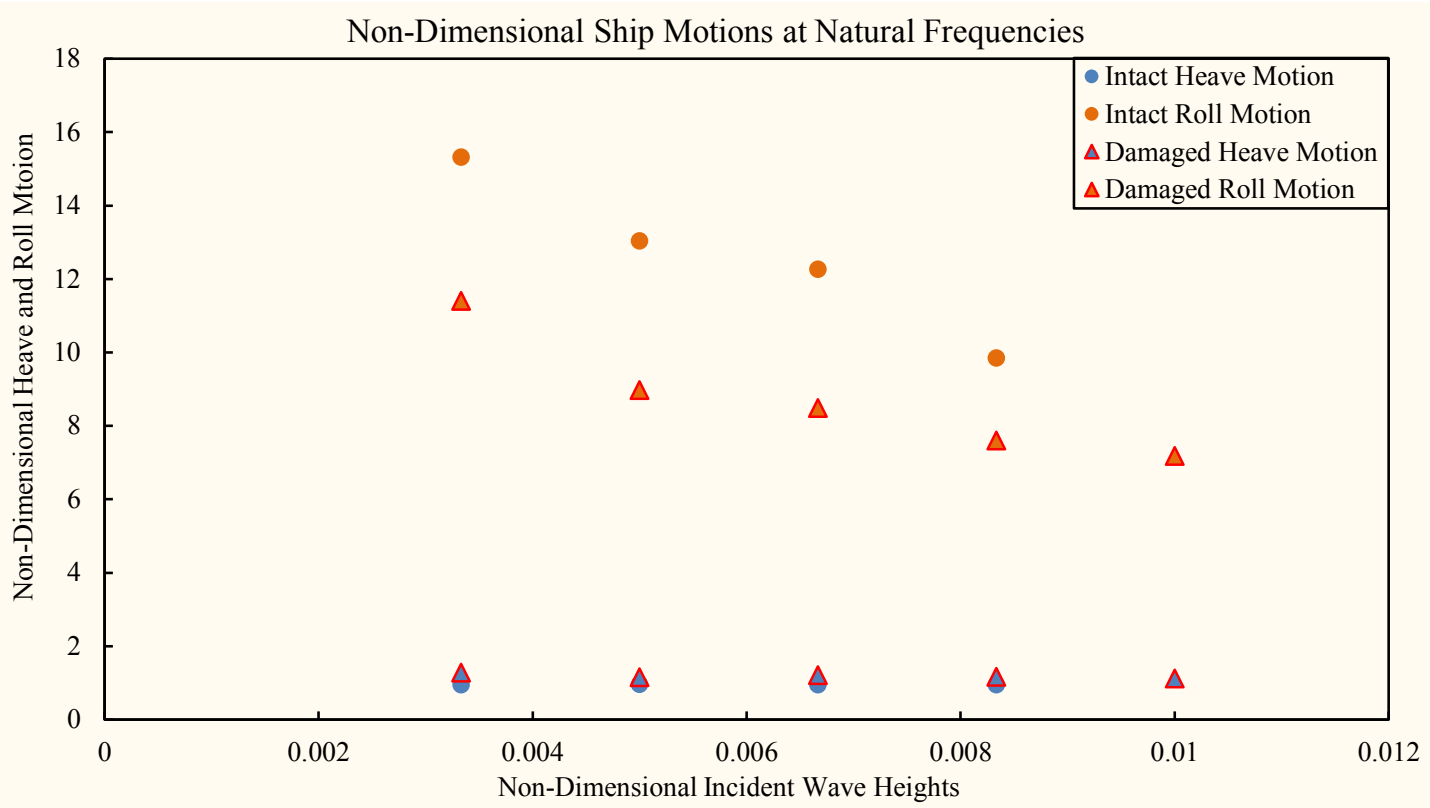

Figure 17. Non-dimensional ship motions with variation of incident wave heights

With various amplitudes of incident waves $(5 \mathrm{~mm}, 7.5 \mathrm{~mm}, 10 \mathrm{~mm}, 12.5 \mathrm{~mm}$ and $15 \mathrm{~mm})$ nondimensionalized by H/Loa (wave heights over ship length) shown in Figure 17, the linearity of heave motion and non-linearity of roll motion can be observed. At non-dimensional natural frequencies of roll motion under the intact and damaged conditions (2.49 and 2.22, respectively) the non-dimensional heave motions do not obviously vary, however, non-dimensional roll motions demonstrate a clear decrease with increase of amplitudes of incident waves.

\subsection{Wave-induced loads}

Figure 18 to Figure 23 illustrate non-dimensional wave-induced loads including shear forces, bending moments and torsional moment on the ship hull in beam waves. Horizontal and vertical shear forces are nondimensionalized by $\rho g A B L$, while horizontal and vertical bending moments and torsional moment are nondimensionalized by $\rho g A B L^{2}$.

The horizontal and vertical shear forces are shown in Figure 18. It can be clearly seen that while damage decreases resonance frequency and amplitude in roll of model hull it raises the amplitude of responding shear force by approximately $50 \%$ compared to the intact scenario. It is also concluded that horizontal shear forces can be bigger than vertical shear forces no matter the ship is intact or damaged. Nonlinearities of horizontal and vertical shear forces can be shown in Figure 19. Similarly, at the natural frequencies of roll motion as amplitudes of incident waves increase horizontal shear force and vertical shear force drop dramatically no matter it is under the intact or the damaged scenario.

Bending and torsional moments acting on intact and damaged ship hull are shown in Figure 20-22. What can be highlighted is that water surface effect plays a significant role to reduce bending moments and torsional moment. It can be seen that a remarkable decrease shown on vertical bending moment and horizontal bending moment by $50 \%$ and $75 \%$, and a $20 \%$ reduction on torsional moment. It is interesting to observe that the interaction between ship motions and floodwater has an apparent influence on wave induced loads as the evaluation of bending moments and torsional moment present a highly nonlinear phenomenon when it is close to natural frequency. This is shown in Figure 23 to give a better description about the nonlinearity on wave-induced loads on the intact and damaged ship triggered by the interaction between floodwater and ship motions. With increases of incident wave heights at natural frequencies of 
roll motion under the intact and damaged conditions wave induced loads show different effect of nonlinearities to each other.

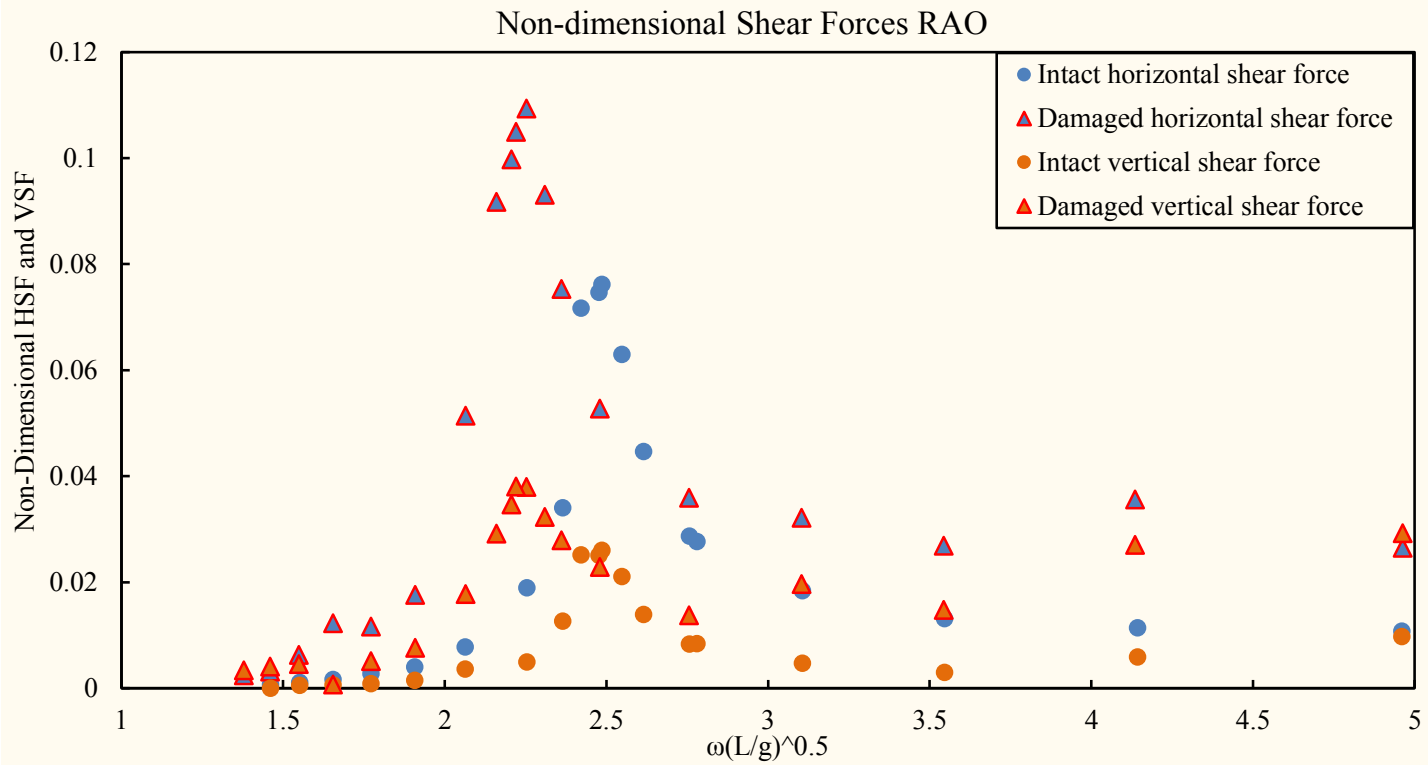

Figure 18. Non-dimensional shear forces

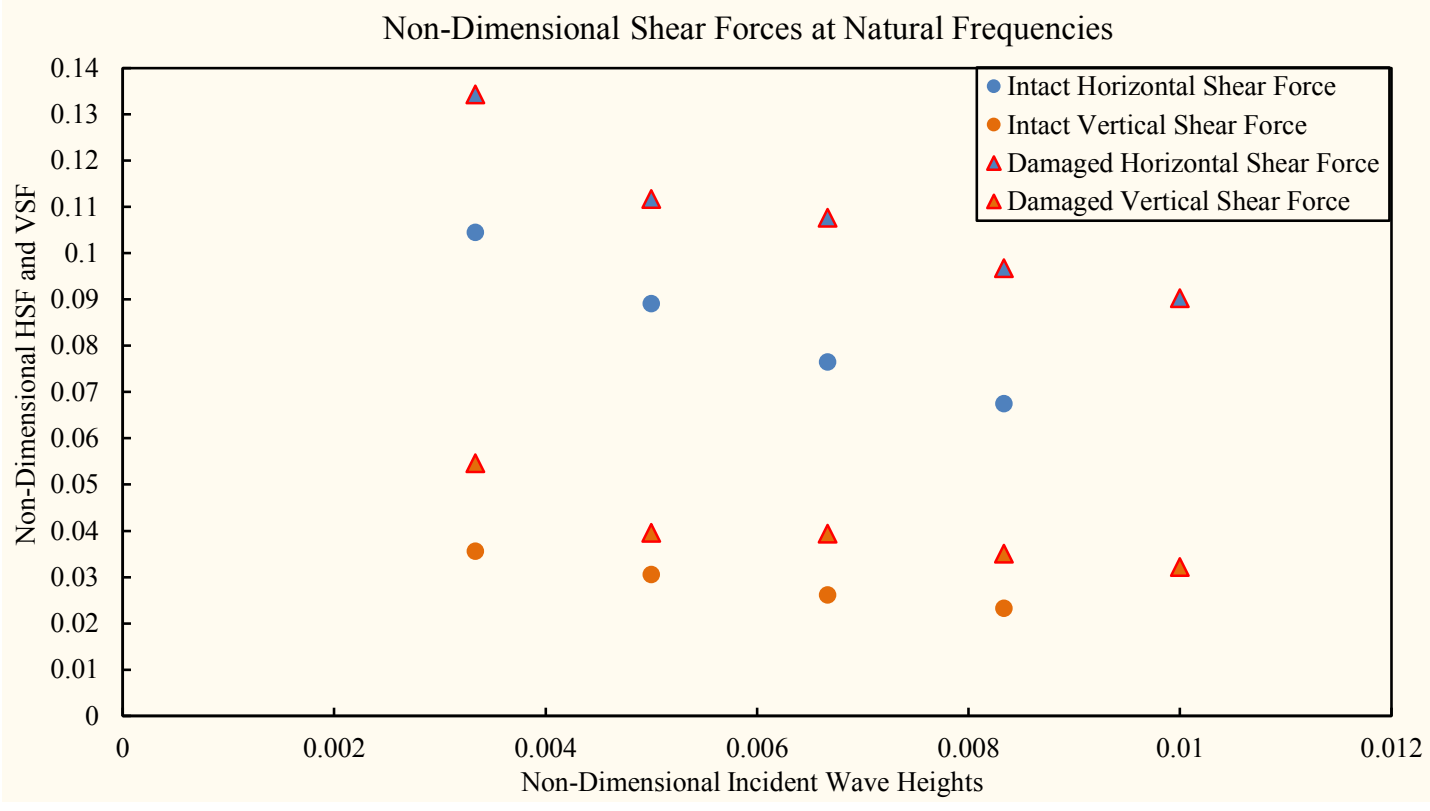

Figure 19. Non-dimensional shear forces with variation of incident wave heights 


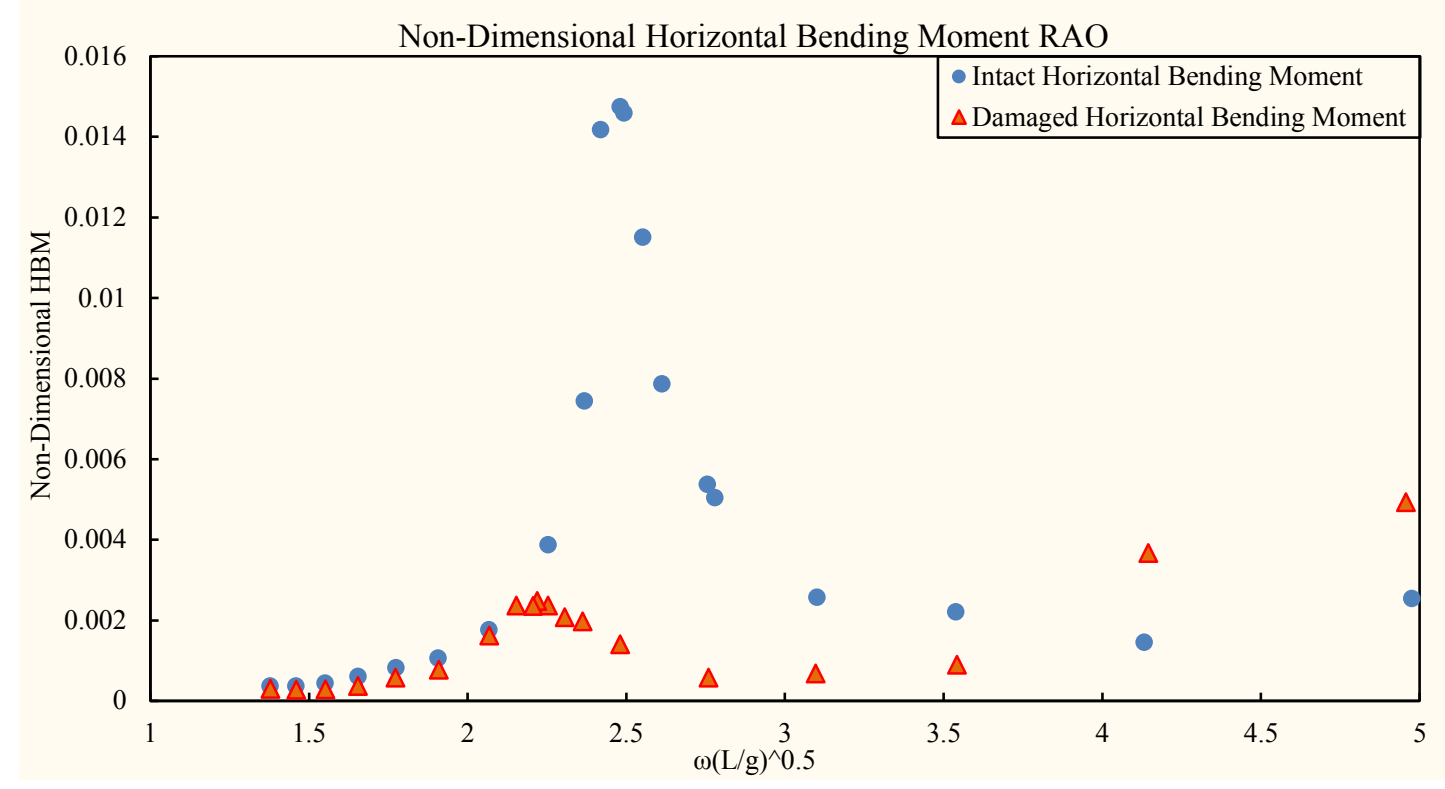

Figure 20. Non-dimensional horizontal bending moment

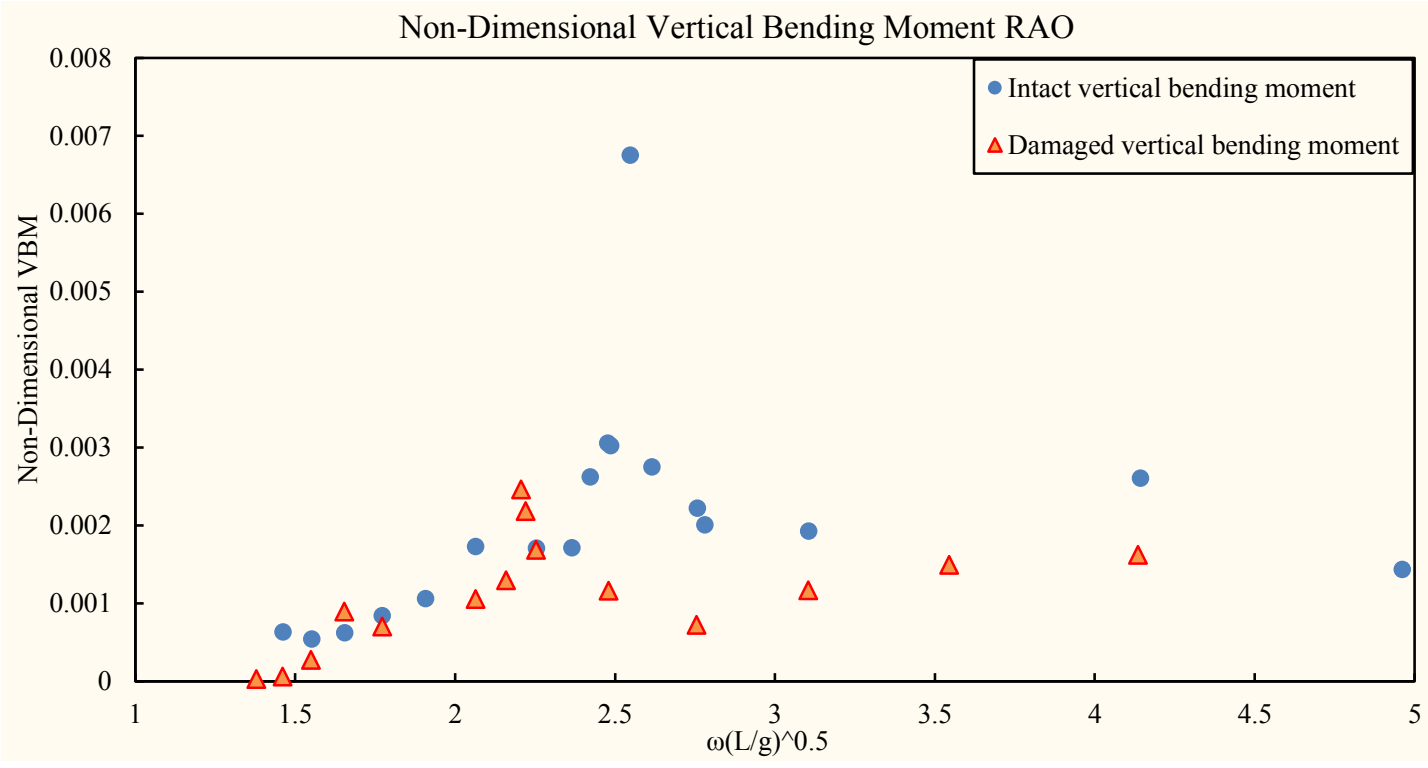

Figure 21. Non-dimensional vertical bending moment 


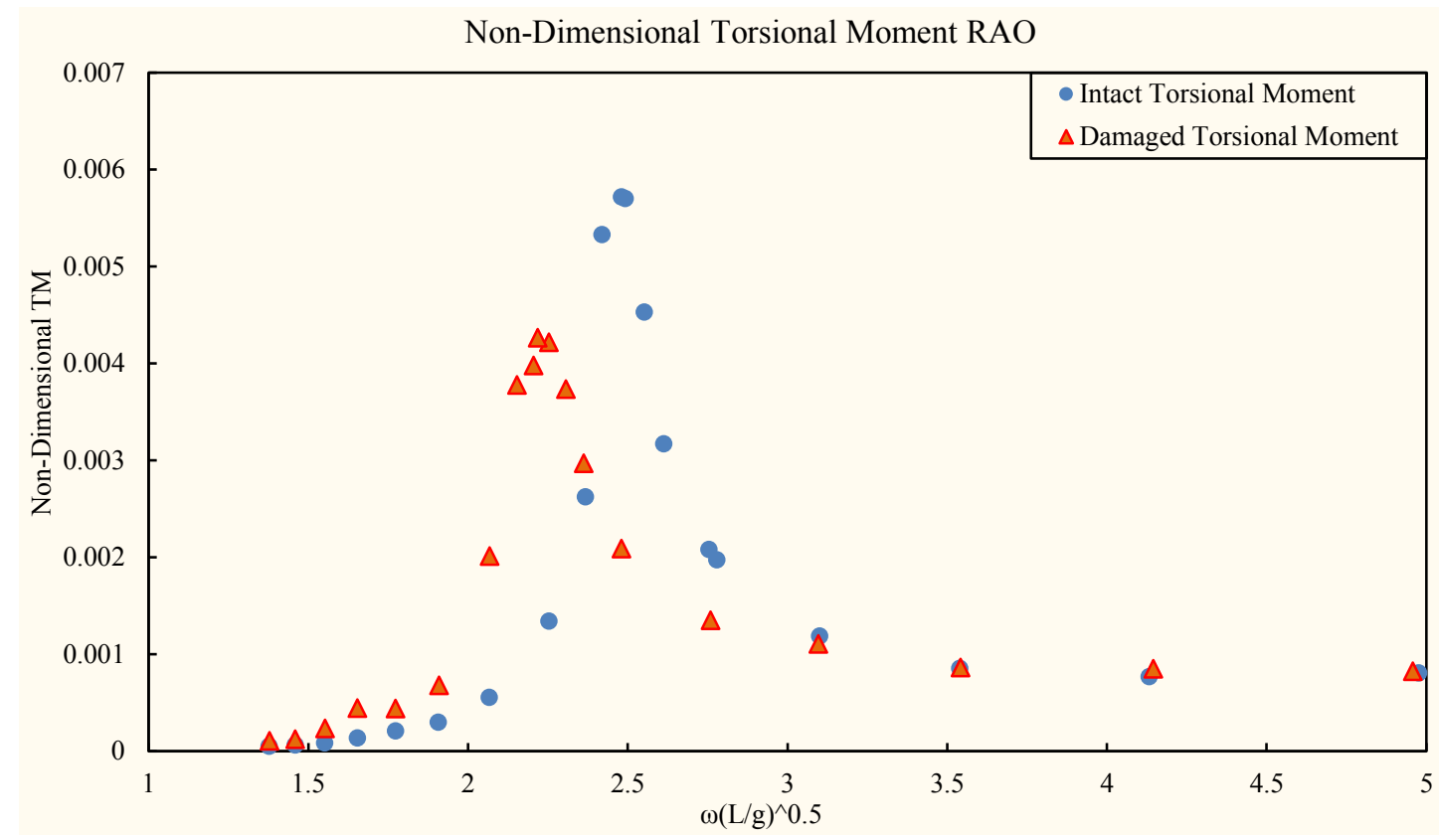

Figure 22. Non-dimensional torsional moment

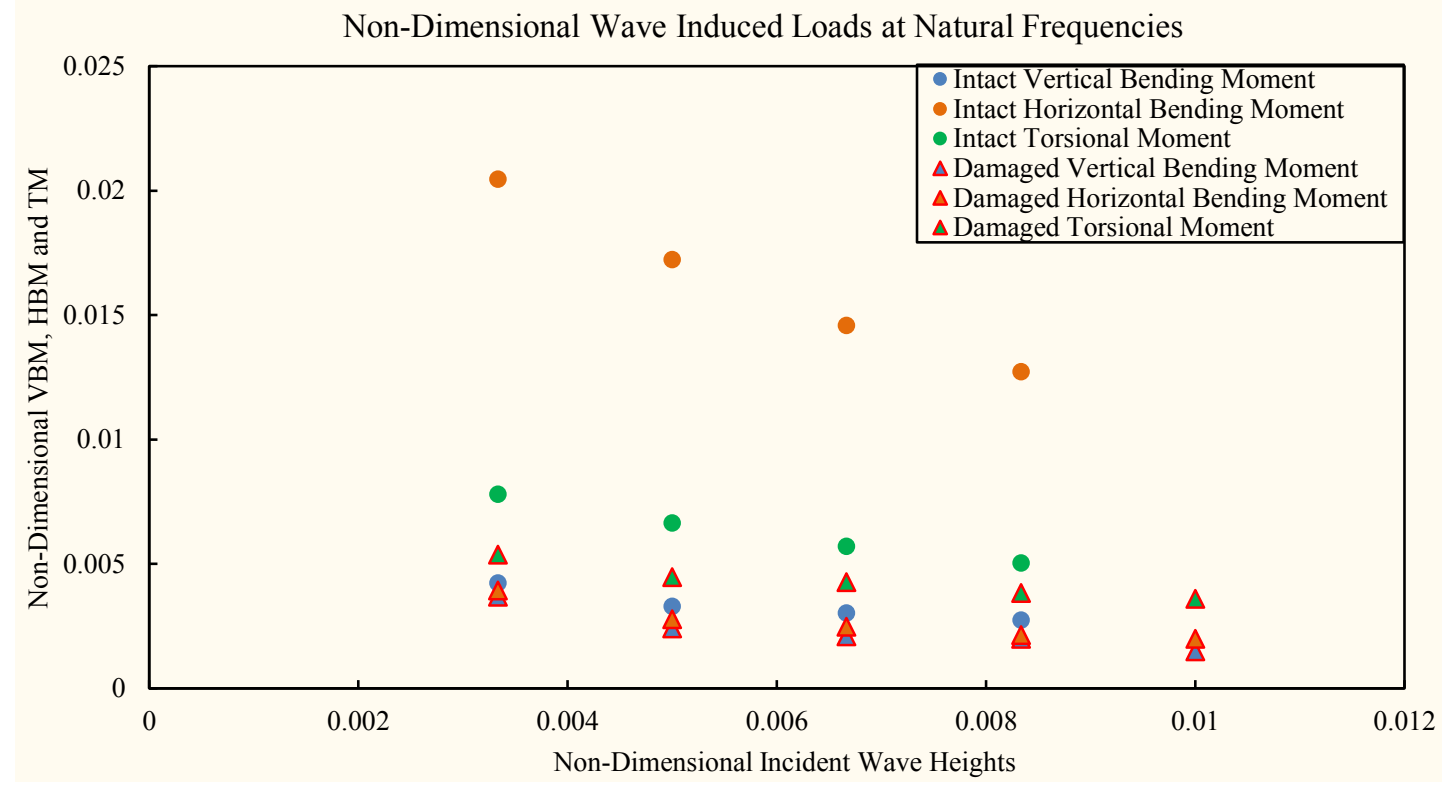

Figure 23. Non-dimensional wave-induced loads with variation of incident wave heights

\section{Conclusion}

An experimental investigation is provided on intact and damaged behavior of a 1/51-scale model of a naval combatant. The ship motion and wave induced loading on the intact and damaged ship hull are measured in calm water and beam seas with zero forward speed. Damaged opening faces to starboard so that two compartments would be flooded but the entire flooding is asymmetric due to a half-unflooded double-bottom tank.

In this study experimental data including ship motions and wave-induced loads of intact and damaged combatant vessel in beam waves is provided to allow validation with numerical methods. The free decay motions in calm water and the motions excited by regular beam waves give the same conclusion that the water surface effect in the damaged compartments has an additional damping impact on ship behaviours compared with intact scenario and resonance frequency of damaged condition is obviously smaller than that of intact condition. However, damaged ship can reach the final stable state within shorter time. In other words, damaged ship stablizes more quickly than intact ship. 
Due to the free surface dynamics in the damaged compartments as well as its interaction with ship motions, highlighted nonlinearities can be obviously observed in roll motions and wave induced loads, but linearity is shown in heave motions of intact and damaged ship hull. According to the results of wave induced loads acting on intact and damaged ship hull, there is a remarkable reducing effect on wave induced bending on the ship model due to existence of water surface in damaged compartments, however, in contrast, shear forces in damaged ship are higher than that of intact cases. This provides authentic benchmark physical experimental investigations on hull girder loads acting on intact and damaged naval combatant ships, and which is able to be effective for validation of investigation with numerical methods further.

\section{References}

Acanfora M, Cirillo A. 2017. A simulation model for ship response in flooding scenario. Proc Inst of Mech Eng Part M J Eng Marit Environ. 231(1):153-164.

Begovic E, Day AH, Incecik A. 2017. An experimental study of hull girder loads on an intact and damaged naval ship. Ocean Eng. 133:47-65.

Bennett SS, Hudson DA, Temarel P. 2013. The influence of forward speed on ship motions in abnormal waves: Experimental measurements and numerical predictions. J Fluids Struct. 39:154-172.

Bennett SS, Hudson DA, Temarel P. 2014. Global wave-induced loads in abnormal waves: Comparison between experimental results and classification society rules. J Fluids Struct. 49:498-515.

Bennett SS, Phillips AB. 2017. Experimental investigation of the influence of floodwater due to ship grounding on motions and global loads. Ocean Eng. 130:49-63.

Chan HS, Atlar M, Incecik A. 2003. Global wave loads on intact and damaged Ro-Ro ships in regular oblique waves. Mar Struct. 16(4):323-344.

De Kat J. 2000. Dynamics of a ship with partially flooded compartment. In: Vassalos D, Hamamoto M, Papanikolaou A, Molyneux D, editors. Contemporary Ideas on Ship Stability. Oxford (UK): Elsevier Publishers; p. 249-263.

de Kat JO, Peters AJ. 2002. Model experiments and simulations of a damaged frigate. IMAM 2002. Proceedings of 10th International Congress Maritime Association of the Mediterranean; May 13-17; Crete. No. 129.

Domeh VDK, Sobey AJ, Hudson DA. 2015. A preliminary experimental investigation into the influence of compartment permeability on damaged ship response in waves. Appl Ocean Res. 52:27-36.

Fujiwara T, Haraguchi T. 2002. On estimation of ship rolling motion with flooded water on vehicle deck. In: Chung JS, Sayed M, Kashiwagi M, Setoguchi T, Hong SW, editors. ISOPE 2002. Proceedings of 12th International Offshore and Polar Engineering Conference. May 26-31; Japan. International Society of Offshore and Polar Engineers. p. 288-294.

Gao Z, Gao Q, Vassalos D. 2011. Numerical simulation of flooding of a damaged ship. Ocean Eng. 38(14):1649-1662.

Khan IA, Das PK. 2008. Reliability analysis of intact and damaged ships considering combined vertical and horizontal bending moments. Ships Offshore Struct. 3(4):371-384.

Kim JS, Roh MI, Ham SH. 2017. A method for intermediate flooding and sinking simulation of a damaged floater in time domain. J Comput Des Eng. 4(1):1-13.

Lee Y, Chan HS, Pu Y, Incecik A, Dow RS. 2012a. Global wave loads on a damaged ship. Ships Offshore Struct. 7(3):237-268.

Lee S, You JM, Lee HH, Lim T, Rhee SH, Rhee KP. 2012b. Preliminary tests of a damaged ship for CFD validation. Int J Nav Archit Ocean Eng. 4(2):172-181. 
Macfarlane GJ, Renilson MR, Turner T. 2010. The transient effects of flood water on a Warship in calm water immediately following damage. Trans R Inst Nav Archit Part A Int J Marit Eng. 152(4):A209A224.

Manderbacka T, Ruponen P, Kulovesi J, Matusiak J. 2015a. Model experiments of the transient response to flooding of the box shaped barge. J Fluids Struct. 57:127-143.

Manderbacka TL, Mikkola TK, Matusiak JE. 2015b. Study of damping effect of the floodwater on a damaged ship roll motion. In: Chung JS, Vorpahl F, Hong SY, Kokkinis T, Wang AM, editors. ISOPE 2015. Proceedings of 25th International Ocean and Polar Engineering Conference. Jun 21-26; USA. International Society of Offshore and Polar Engineers.

Manderbacka T, Ruponen P. 2016. The impact of the inflow momentum on the transient roll response of a damaged ship. Ocean Eng. 120:346-352.

Palazzi L, De Kat J. 2004. Model experiments and simulations of a damaged ship with air flow taken into account. Mar Tech. 41(1):38-44.

Papanikolaou A, Zaraphonitis G, Spanos D. 1999. Numerical and experimental study on the capsizing of damaged ro-ro passenger ships in waves. Proceedings of International Workshop on Nonlinear Wave-Body Interaction Problems; Dec 2-3; Japan. Research Institute of Applied Mechanics.

Papanikolaou A, Zaraphonitis G, Spanos D, Boulougouris E, Eliopoulou E. 2002. Investigation into the capsizing of damaged Ro-Ro passenger ships in waves. In: Renilson M, editor. STAB 2000. Proceedings of 7th International Conference on Stability of Ships and Ocean Vehicles; Feb 7-11; Australia. p. 351-362.

Papanikolaou A, Spanos D. 2004. 24th ITTC benchmark study on numerical prediction of damage ship stability in waves preliminary analysis of results. In: Huang X, Miao G, Zhu R, editors. Proceedings of Seventh International Workshop on Stability and Operational Safety of Ships, November 1-3; Shanghai.

Rodrigues JM, Soares CG. 2017. Still water vertical loads during transient flooding of a tanker in full load condition with a probabilistic damage distribution. Ocean Eng. 129:480-94.

Ruponen P. 2006. Model tests for the progressive flooding of a box-shaped barge. [place unknown]: Helsinki (FINL): Helsinki University of Technology. ISBN-9512282283.

Ruponen P. 2007. Progressive flooding of a damaged passenger ship [dissertation]. Helsinki (FINL): Helsinki University of Technology.

Santos TA, Winkle IE, Soares CG. 2002. Time domain modelling of the transient asymmetric flooding of Ro-Ro ships. Ocean Eng. 29(6):667-88.

Santos TA, Soares CG. 2008a. Global loads due to progressive flooding in passenger ro-ro ships and tankers. Ships Offshore Struct. 3(4):289-303.

Santos TA, Soares CG. 2008b. Study of damaged ship motions taking into account floodwater dynamics. J Mar Sci Tech. 13(3):291-307.

Wu M, Hermundstad OA. 2002. Time-domain simulation of wave-induced nonlinear motions and loads and its applications in ship design. Mar Struct. 15(6):561-97. 